D. DOE/ER/52152--2

DE91 001987

\title{
TRITIUM INVENTORY TRACKING AND MANAGEMENT
}

\author{
FINAL REPORT \\ FOR \\ U. S. DEPARTMENT OF ENERGY \\ GRANT DE-FG06-88ER52152 \\ INNOVATIVE FUSION REACTOR DESIGN ANALYSIS
}

THOMAS W. EICHENBERG

ANDREW C. KLEIN

DEPARTMENT OF NUCLEAR ENGINEERING

OREGON STATE UNIVERSITY

CORVALLIS, OR 97331

SEPTEMBER 10,1990

\section{DISCLAIMER}

This report was prepared as an account of work sponsored by an agency of the United States Government. Neither the United States Government nor any agency thereof, nor any of their employees, makes any warranty, express or implied, or assumes any legal liability or responsibility for the accuracy, completeness, or usefulness of a $y$ information, apparatus, product, or process disclosed, or represents that its use would not infringe privately owned rights. Reference herein to any specific commercial product, process, or service by trade name, trademark, manufacturer, or otherwise does not necessarily constitute or imply its endorsement, recommendation, or favoring by the United States Government or any agency thereof. The views and opinions of authors expressed herein do not necessanily state or reflect those of the United States Government or any agency thereof. 


\subsection{INTRODUCTION}

This report details the research carried out under the second year of the United States Department of Energy grant DE-FG06-88ER52152 to the Department of Nuclear Engineering at Oregon State University.

\subsection{TRITIUM BREEDING RATIO CONTROL AND INVENTORY MANAGEMENT}

The requirement for tritium self-sufficiency in a DT fusion reactor system has been analyzed in detail by a number of investigators ${ }^{1,2,3,4}$. These studies have focused on the calculation of the minimum initial tritium inventory required to maintain a sufficient supply of tritium for the reactor during the startup of the system, and on the length of time required to double the initial tritium inventory. Such analysis has centered on the evaluation of the minimum tritium breeding ratio needed to maintain the tritium supply in the system, and on the analysis of the dynamics of the initial startup of the reactor system including variations of the time constants used to describe the flow of tritium through the blanket, coolant processing, and plasma impurity processing subsystems. The previous analysis usually was terminated once the minimum external inventory of tritium was passed and the blanket processing system produces encugh tritium to compensate for those tritium atoms burned in the plasma, lost by decay, or lost during processing. During the subsequent time periods the total storage inventory was typically allowed to increase. Consideration was then given to developing the relationships necessary to determine the doubling time, or the time that is needed to have sufficient tritium available in order to start up another fusion reactor plant.

The assumption that each reactor is responsible for producing the inicial fuel supply for other reactors automatically puts any electric utility which operates a UT fusion based power reactor in the tritium fuel supply business. With the inconveniences involved in containing and transporting tritium, and the obvious environmental concerns surrounding its use, transportation, and storage in large quantities, an individual electric utility may decide that the supply of fuel for other reactor systems may not be worth the costs over the long run. Alternatively, a DT fusion power plant may be operated such that there is no net increase in stored tritium for a number of years, and then operated in such a 
mode to produce adequate tritium supplies for the startup of one additional reactor system. In this way, the system would be operated initially in a tritium recycling mode, and then converted to run for a limited period of time in a tritium production mode. Also, in a mature fusion industry, it may be advantageous to limit the amount of excess tritium for safety and environmental reasons. Thus, the control of the tritium supply in the fusion reactor system, to limit the amount of excess tritium handled on site, and maintained in the tritium storaye system, may be considered to be important.

The control of the tritium breeding ratio (TBR) in a DT fusion reactor system is the one area of the tritium cycle which the design engineer has any control over the amount of tritium produced. By varying the TBR. the reactor systems design engineer can determine the rate at which tritium is produced. Should excess tritium be needed for the startup of additional plants, then the TBR can be increased, or should the need for replacement tritium (to replace that lost by decay and processing losses) satisfy the needs of the utility, then the TBR can be reduced to a level sufficient to provide the required makeup.

Analysis has been developed to address two basic questions:

1. How must the tritium breeding ratio of the reactor blanket be adjusted during operation to reduce the amount of excess tritium to be stored?

2. What effects on the overall tritium handling system, and consequently the operation of the plant, are observed due to transients (failures) in various components of the tritium processing system?

The present analysis includes an assessment of the variations in the tritium breeding ratio necessary to reduce the amount of excess tritium needing storage. The first question above deals with modifications that need to be made in a fusion reactor blanket to either reduce or increase the tritium breeding ratio in the blanket to compensate for too much or too little tritium production. The insertion or withdrawal of small amounts of parasitic neutron absorbers in 
the blanket could be used to accomplish this task, however this may add considerable complexity to some blanket designs. In a self-cooled blanket configuration in which the coolant is also used as the tritium breeding material, the addition and dilution of neutron absorbers in the coolant/breeding material can be readily achieved. However, for other configurations, such as those using solid breeding materials, this may not be possible. Poison concentrations can be varied in the coolants of such systems if such additions are compatible with blanket structural components.

An alternative to such an active TBR control is possible, since there is typically a significant storage capacity designed into each tritium processing system. Instead of the active control mechanisms stated above, it would be possible to change: the characteristic TBR of the overall blanket system each time the reactor is shut down and blanket segments are replaced. For example if additional tritium would be needed for the startup of additional reactor plants, then an increase in the average TBR could be accomplished by adding blanket segments with TBR values considerably greater than unity. These considerations will require further study.

Analysis has been conducted to explore a variety of reactor system operational parameters and modes including:

1. Verification of computer program operation.

2. The effects of varying the tritium breeding ratio on the tritium inventory throughout the plant.

3. Varying the TBR to achieve a constant storage inventory after a period of operation to restore the initial, or start up, inventory.

4. The effects of actual operational cycles including an annual shut down for blanket replacement and routine maintenance.

5. The effects of failures of various components within the tritium processing stream. 
6. Scenarios for the generation of start up tritium for additional plants.

Thus, the principal objective of this investigation is to examine some of the potential operational modes of the tritium handling system in a DT based fusion power plant, and to identify some of the areas that will be important to the development of electrical energy producing fusion power plants.

\subsection{MODEL DEVELOPMENT}

Abdou, et $a 1^{4}$ have developed the differential equations and time dependent analytical solutions for a 9 component tritium breeding and processing system, and have analyzed the tritium breeding and system requirements for a number of specific cases. The present effort has used the same organization and equations to develop a computer model (TBRCON) to numerically analyze the questions posed abo:e.

Figure 1 shows schematically how the various components of the tritium processing system considered in this analysis are connected to each other. Table 1 lists the resulting first order linear differential equations which are developed for this organization of the tritium processing system of a generic fusion reactor. Table 2 defines the variables used in the equations and lists some of the parameters used in the following analysis, and Table 3

lists the tritium system components considered in the analysis. Table 4 shows many of the parameters used in the following calculations. The organization, equations, and input, data values are very similar to those used in reference 4 , thus the assumptions from the original development of the system of equations are a1so applicable here.

In general, the equations of Table 1 can be combined into a matrix notation of the form

$$
\frac{\partial I(t)}{\partial t}=\tilde{A}(t) I(t)+\tilde{S}(t)
$$




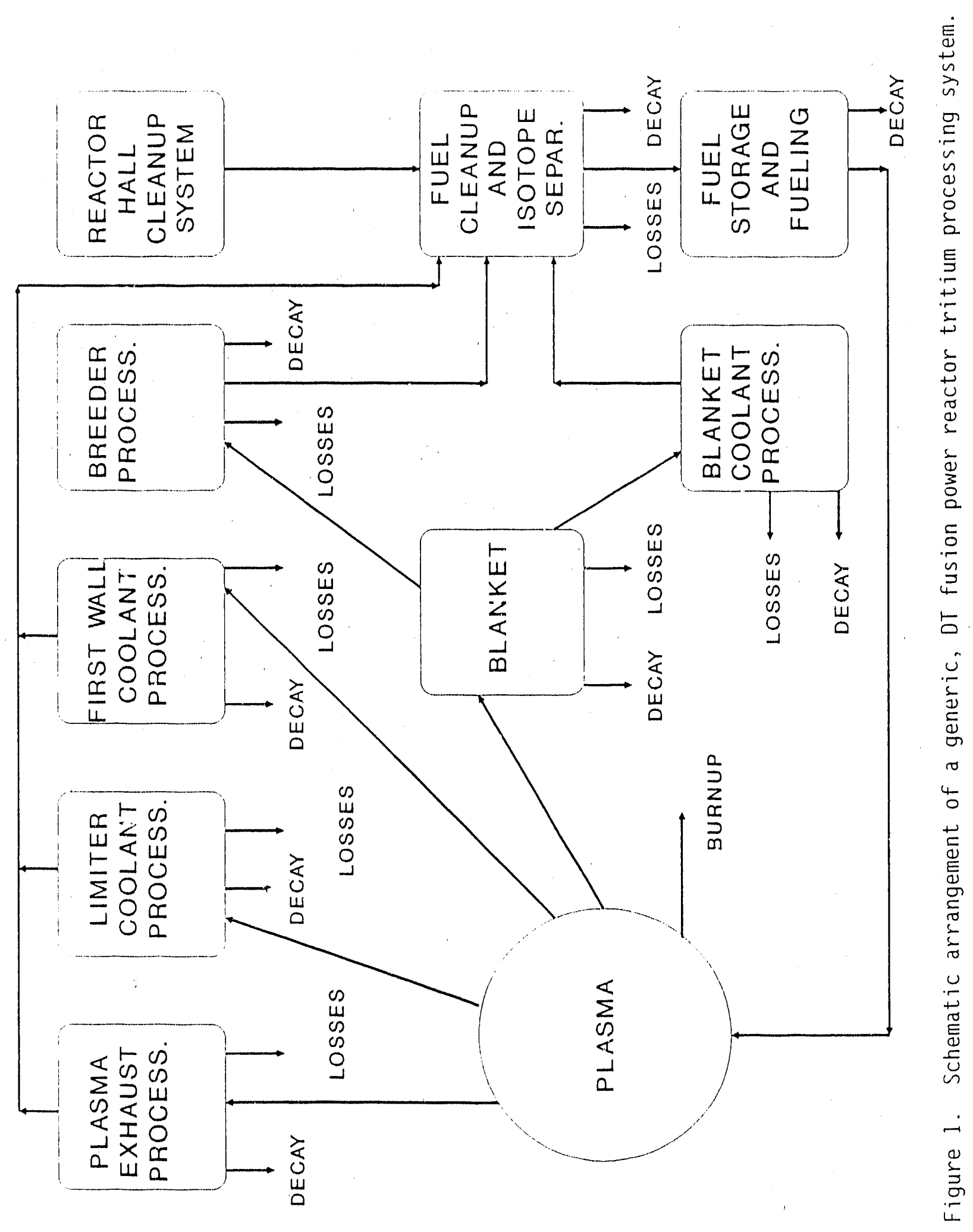


Table 1. Tritium inventory equations for each system component.

1. Blanket System

$$
\frac{d I_{1}}{d t}=\Lambda \dot{N}-\left(\frac{1+\epsilon_{1}}{T_{1}}+\lambda\right) I_{1}
$$

2. Breeder Processing System

$$
\frac{d I_{2}}{d t}=\left(1-f_{c}\right) \frac{I_{1}}{T_{1}}-\left(\frac{1+\epsilon_{2}}{T_{2}}+\lambda\right) I_{2}
$$

3. Blanket Coolant Processing. System

$$
\frac{d I_{3}}{d t}=f_{c} \frac{I_{1}}{T_{1}}-\left(\frac{1+\epsilon_{3}}{T_{3}}+\lambda\right) I_{3}
$$

4. Fuel Cleanup and I sotope Separation Systems

$$
\frac{d I_{4}}{d t}=\frac{I_{2}}{T_{2}}+\frac{I_{3}}{T_{3}}+\frac{I_{6}}{T_{6}}+\frac{I_{7}}{T_{7}}+\frac{I_{8}}{T_{8}}+\dot{I}_{9}-\left(\frac{1+\epsilon_{4}}{T_{4}}+\lambda\right) I_{4}
$$

5. Fuel Storage and Fueling Systems

$$
\frac{d I_{5}}{d t}=\frac{I_{4}}{T_{4}}-\frac{\dot{N}}{\beta}-\lambda I_{5}
$$

6. Plasma Exhaust Processing System

$$
\frac{d I_{b}}{d t}=\frac{\dot{N}}{\beta}\left(1-\beta-f_{L}-f_{F}\right)-\left(\frac{1 \cdot \epsilon_{6}}{T_{6}}+\lambda\right) I_{6}
$$

7. Limiter Coolant Processing System

$$
\frac{d I_{7}}{d t}=f_{L} \frac{\dot{N}}{\beta}-\left(\frac{1+\epsilon_{7}}{T_{7}}+\lambda\right) I_{7}
$$

8. First Wall Coolant Processirig System

$$
\frac{d I_{8}}{d t}=f_{F} \frac{\dot{N}}{\beta}-\left(\frac{1+\epsilon_{8}}{T_{8}}+\lambda\right) I_{8}
$$


Table 2. Nomenclature.

$I_{i}=$ Tritium inventory in component $i(g)$

$\Lambda=$ Tritium breeding ratio

$\dot{N}=$ Tritium burnup rate $(\mathrm{g} / \mathrm{s})$

$T_{i}=$ Mean residence time in component I ( $s$ )

$\lambda=$ radioactive decay constant $\left(1.5436 \times 10^{-4} \mathrm{~s}^{-1}\right)$

$\epsilon_{i}=$ Non-radioactive loss fraction from component $i$

$\beta=$ Tritium burn fraction in plasma

$\dot{I}_{9}=$ Tritium returned from reactor hall cleanup system $(\mathrm{g} / \mathrm{s})$

$f_{L}=$ Tritium leakage fraction from plasma to 1 imiter coolant system

$f_{F}=$ Tritium leakage fraction from plasma to first wall coolant system

$f_{c}=$ Tritium leakage fraction from breeder material to blanket coolant system 
Table 3. Component identification.

\begin{tabular}{|c|c|}
\hline $\begin{array}{l}\text { Component } \\
\text { Number } \\
\end{array}$ & Component Name \\
\hline 1 & Blanket System \\
\hline 2 & Breeder Processing System \\
\hline 3 & Blanket Coolant Processing System \\
\hline 4 & Fuel Cleanup and Isotope Separation Systems \\
\hline 5 & Fuel Storage and Fueling Systems \\
\hline 6 & Plasma Exhaust Processing System \\
\hline 7 & Limiter Coolant Processing System \\
\hline 8 & First Wall Coolant Processing System \\
\hline 9 & Reactor Hall Cleanup System \\
\hline
\end{tabular}


Table 4. Data used as input to TBRCON.

$\begin{array}{lcc}\text { Component } & \begin{array}{c}\text { Mean Residence } \\ \text { Time (days) }\end{array} & \begin{array}{c}\text { Non-Radioactive } \\ \text { Loss Factor }\end{array} \\ \begin{array}{l}\text { Blanket } \\ \text { Breeder Processing }\end{array} & 10 & 0.0 \\ \text { Blanket Coolant Processing } & 1 & 0.0101 \\ \text { Fuel Cleanup } & 100 & 0.0101 \\ \text { Fuel Storage } & 0.1 & 0.0 \\ \text { Plasma Exhaust } & 0.01 & 0.0 \\ \text { Limiter Coolant } & 1 & 0.001 \\ \text { First Wall Coolant } & 100 & 0.001\end{array}$

Breeder to Blanket Coolant Leakage Fraction 0.01

P1asma to Limiter Coolant Leakage Fraction 0.0001

Plasma to First Wail Coolant Leakage Fraction 0.0001

Tritilum Burn Rate $\quad 500 \mathrm{~g} / \mathrm{day}$

Tritium Recovery from Reactor Hull $0.01 \mathrm{~g} /$ day 
where the tritium inventory vector is defined as

$$
\vec{I}(t)=\left(\begin{array}{c}
I_{1} \\
I_{2} \\
\vdots \\
I_{8}
\end{array}\right)
$$

the tritium source vector is given as

$$
S(t)=\left(\begin{array}{c}
\dot{N} \\
0 \\
0 \\
\dot{I}_{9} \\
-\frac{\dot{N}}{\beta} \\
\frac{\dot{N}}{\beta}\left(1-\beta-f_{L}-f_{F}\right) \\
f_{L} \frac{\dot{N}}{\beta} \\
f_{F} \frac{\dot{N}}{\beta}
\end{array}\right)
$$

and the tritium transfer matrix, $\dot{A}(t)$, is a square matrix which includes the various transfer and loss mechanisms between the components of the tritium processing system. Note that since each component is not directly connected to a11 other system members this tritium transfer matrix will be relatively sparse.

A matrix exponential solution technique ${ }^{5,6}$ has been used to solve the resulting set of first order linear differential equations for the inventory of tritium in each of the tritium processing components as a function of time. This time dependent solution technique has been found to be very useful in a number of applications in the past, including the calculation of the movement of fission 
products released into a reactor containment building, ${ }^{7.8}$ and in the RAPTOR $^{9,10,11}$ fusion reactor activation product transport code.

\subsection{CODE DESCRIPTION}

This section describes the different numerical programs which have been used in this study. The primary calculational tool for the TBR study is a FORTRAN77 program named TBRCON. This program is used as a subroutine by a driver spreadsheet in SYMPHONY. The driver spreadsheet for SYMPHONY is created by the user from a master template worksheet. All of the user interaction for code operation is performed from within SYMPHONY.

\subsection{FORTRAN SUBROUTINE TBRCON}

The FORTRAN subroutine TBRCON is used to solve the coupled set of ordinary differential equations outlined above for the tritium inventory in each system compartment as a function of time. The source code to be compiled for this subroutine is found in the disc operating system, (DOS), file: TBR.FOR. The executable subroutine is found in DOS file TBR.EXE.

Tile TBRCON subroutine requires access to three additional, external files. These three files must reside in the same DOS directory as the executable file, not in a sub-directory or parent directory. The first cos file which must be accessed is TRITIUM.PRN which contains the initial inventory record for each compartment of the fusion system. The second DOS file which must be accessed is TBRINP.PRN. This file contains the operational parameters of the fusion system. These include such items as the non-radiative loss fractions and the mean residence time for each compartment, along with other parameters like the tritium breeding ratio for the system and the plasma consumption rate. Additional description of the input will be discussed in section 4.5. The third DOS file which requires access is named TBROUT. This file will contain the calculated tritium concentrations for each system compartment at the end of the predetermined time step. 
None of the above described programs or files are directly called or entered by the code user. All manipuiation of the FORTRAN subroutine and its attendant holding files is done by the driving macros within SYMPHONY.

\subsection{SYMPHONY SPREADSHEET}

As mentioned above, SYMPHONY is used to drive the entire analysis. The SYMPHONY package by LOTUS is defined as an integrated software program. The program contains a spreadsheet, word processing, graphics, database, and communications modules. For these calculations, only the spreadsheet, graphics, and database capabilities of the program are needed. One of the major advantages of SYMPHONY over other spreadsheet type programs, such as LOTUS 1-2-3 and QUATTRO, is the windows capability. This capability allows the user to see different parts of the spreadsheet at the same time on the screen.

\subsection{DATABASE}

The code used in the analysis has two separate databases to represent the fusion system. The first database, named 'INPUT', is for the operating parameters of the system as a function of time; input information for the FORTRAN subroutine are generated from this database. The second database, named 'OUTPUT', presents the tritium concentrations in the various system compartments as a function of time. The results of the TBRCON calculation are stored in this database. The graphical representation of results then uses this database for compartment tritium data.

\subsection{GRAPHICS}

There are two different sets of graphics result representations. Both sets are applied to each system compartment. The first set, called 'RECENT', shows the compartment tritium concentrations for the past six output records in the 'OUTPUT' database. The second set of graphical results shows the complete time history for compartment tritium concentrations, and is found 
under the set named 'COMPLETE'. A third, menu accessible, graphics window is available under the menu name 'GENERAL'. This window is open for any graph use which the user would like. All of these graphic options are to be found by accessing the SYMPHONY ALT D menu.

\subsection{CODE OPERATIONS}

The operation of this code is fairly straightforward. The first thing one needs to do is to retrieve the source worksheet. This worksheet name is 'TEMPLATE.WR1'. After retrieving the source worksheet, an autoexecutable macro should have attached the DOS application and moved to the 'INPUT' database. Now it is necessary for the user to generate input deck records for the TBRCON routine. This is done by editing the individual fields of the 'INPUT' database. once a record is finished, this record needs to be placed into the atabase. This is done by pressing the insert button on the keyboard. After pressing the insert button, a new record sheet wi11 be presented on the screen for editing. Note: make sure that the identification number of the record corresponds to the numerical order in which the records are to be to be processed. Any integer number may be used to begin the identification numbering. However, the numbering of the records to be processed must be in sequential order.

Once the 'INPUT' database is filled in, to user needs to go to the command menu for operating the code. This is done by pressing ALT M, and then choosing the 'OUTPUT' command which takes the user to the 'OUTPUT' database. The first record of this database must ve filled with the initial tritium source inventory in each compartment. Use the insert button on the keyboard to enter the record into the database.

Return to the 'INPUT' database by choosing the 'INPUT' command from the menu. The source file must now be initialized for the TBRCON routine. This is done by choosing the 'SOURCE' command from the menu options. After initializing the source, the user needs to set up the system parameter file. This is done by choosing the 'PREPARE' command from the menu options. 
The code is now ready to run. Select the ' $\mathrm{GO}$ ' command from the menu and answer the prompted questions. The code will ask for the numerical identification number of the starting and finishing input record. If it is desired to run just one record, then the starting and finishing number are the same.

\subsection{RESULTS}

This section presents the results of the different numerical experiments which were run to test the operation of the code. These range from verification of the numerical method by comparison with the analytical results presented by Abdou, et al to system breakdown and failures, and excess production of tritium for the startup of additional reartor systerns.

\subsection{REFERENCE VERIFICATION}

The purpose of this section is to show that the solution of the governing differential equations for the system is the identical to the analytical solutions presented in reference 4. In particular, the goal of the code verification studies is based upon the ability to reproduce figures 2 and 3 presented by Abdou, et al. These two figures present the mass of tritium as a function of time for several different sub-systems. These figures show the differing requirements on the tritium system as a function of the plasma burnup fraction.

The comparable results from the numerical solution of the governing equations for a plasma beta value of 0.05 is given in Figure 2 . It can be shown that a comparison of these results with those of the analytical solution provides excellent agreement. Figure 3 shows the results of the numerical calculations for a plasma beta of 0.10 . A comparison of these results with the analytical solution of reference 4 also shows excellent agreement.

Based upon the agreement between the verification calculations, it can be concluded that the solution method employed by this study to solve the governing differential equations produces results which are identical to those of the 


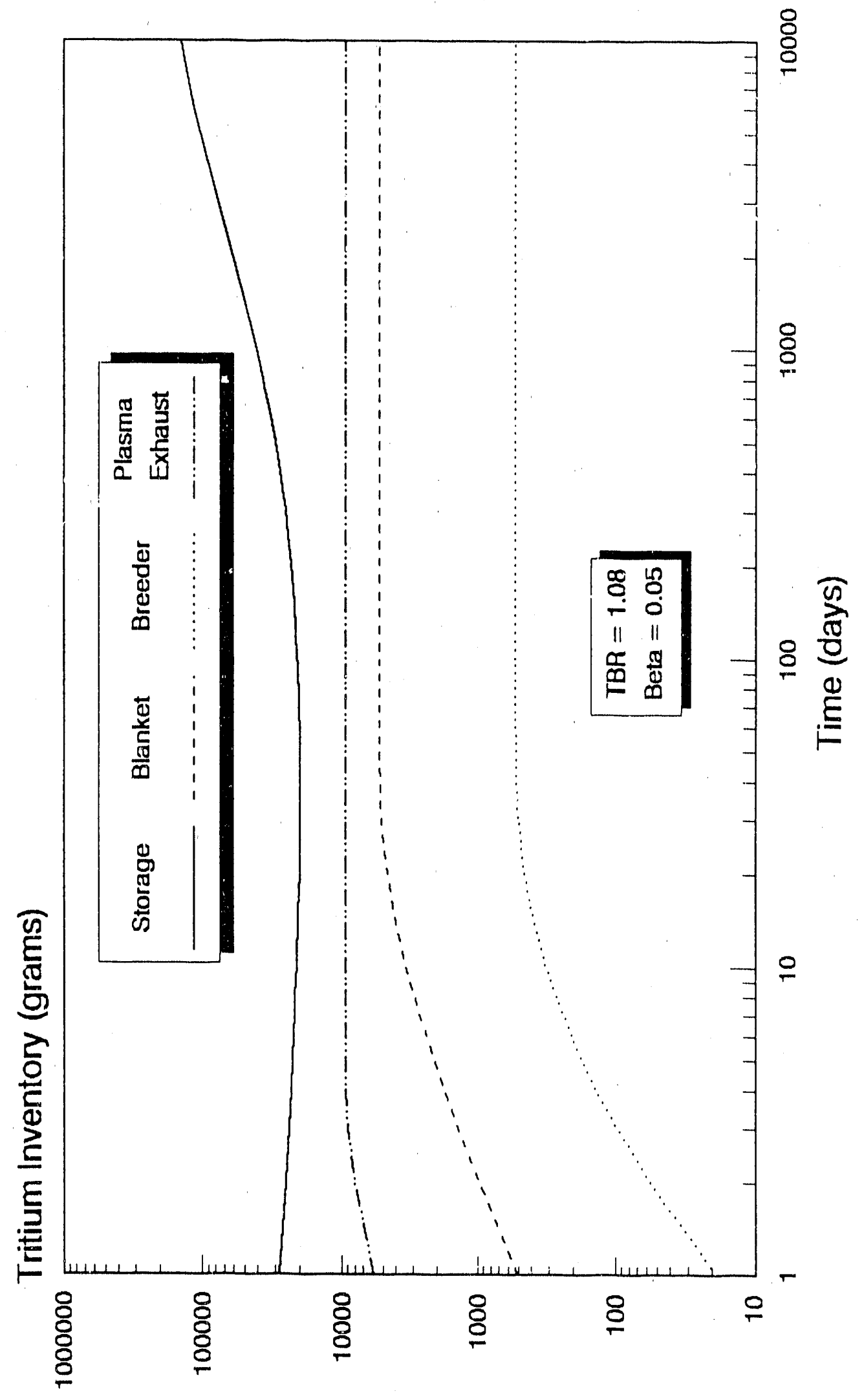

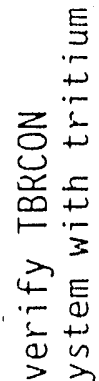

ㅎํ

$\stackrel{\bigotimes}{\underline{E}}$

$\mp 0$

4 品

등

I0

U U

넌원은

त 4

ก它

궁

ฮِ

¿

E号

$\because 40$

$=0$ r

千N

比

$=$ Ğ

- L -

苗市

$\Xi \pm$

$\frac{1}{4} \div$

б

ㄴ․․․

के

㤐造

$\dot{\sim}$

$\stackrel{0}{5}$ 


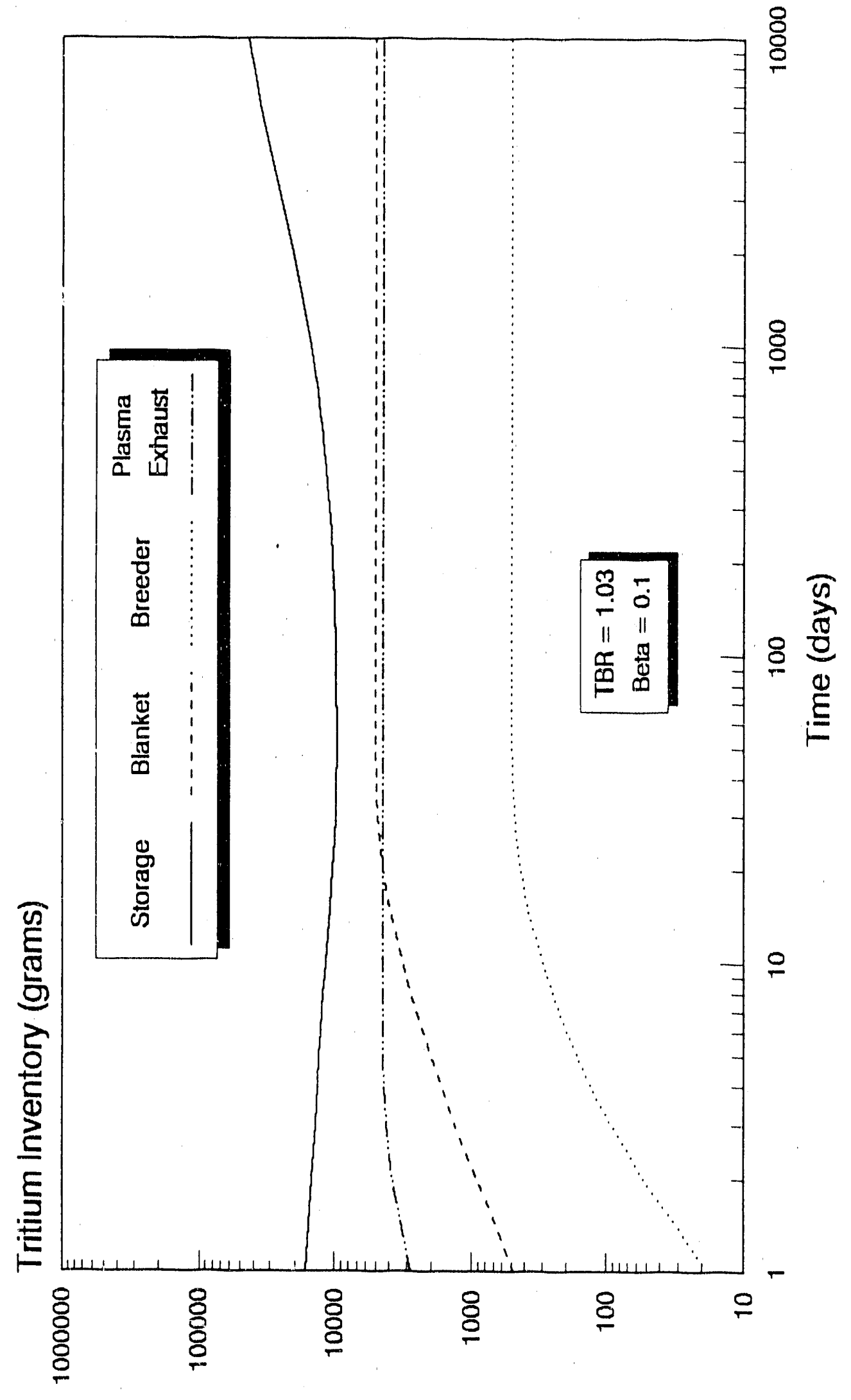

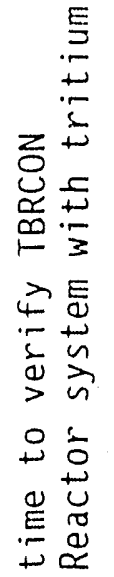

4.0

$=\widehat{\sigma}$

는

บัฐ

पे के

○ष्

क

ริำ

艺这

$\geq$

그욜

튼웅

$\$ 40$

50

w $m$ 只

○ฏ

ธ. 잉

$\therefore-1$

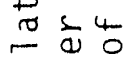

$\Xi \pm$

$\frac{1}{10} \ll \stackrel{0}{1}$

0.

万o

ㄴ.

50

है व

글응

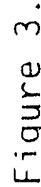


analytical solutions given by Abdou et al.

\subsection{TRITIUM STORAGE STABILIZATION}

A series of parametric studies was performed to observe the effects of variations of the TBR upon the system storage requirements. The TBR was varied from the reference case values between $+10 \%$ and $-30 \%$ for both values of the plasma burnup fraction presented above. The purpose of this study was to identify the value of TBR which would hold the tritium concentration constant in the storage compartment.

Figure 4 shows the effects upon the storage requirements for a $10 \%$ increase in TBR over the reference value of 1.08 for a reactor system with a plasma beta of 0.05 . Figure 5 presents the effect upon the storage requirements for a $30 \%$ decrease in TBR below the reference value for the same reactor system. These results show the sensitivity of the system to different TBR values. It also shows that the TBR must be slightly greater than 1.00 in order to recover the initial tritium stockpile.

Figure 6 shows the effects on the tritium storage requirements for a $10 \%$ increase in TBR over the reference value of 1.03 for a reactor system with a plasma burnup fraction of 0.10 , and Figure 7 demonstrates the effects on the storage requirements for a $30 \%$ decrease in TBR below the reference value. Again, these results show the sensitivity of the system to different TBR values.

Using the parametric variation results for the system, the next step was to determine the TBR which produces a stable tritium inventory in the storage compartment. After a trial and error search for stable TBR values it was fourid that a TBR value of 1.036 is required to maintain a constant tritium storage inventory for a reactor system operating with a plasma burnup fraction of 0.05 . Additional searches show that the TBR required to hold the storage inventory constant for a reactor system with a plasma burnup fraction of 0.10 is approximately 1.0195 . 


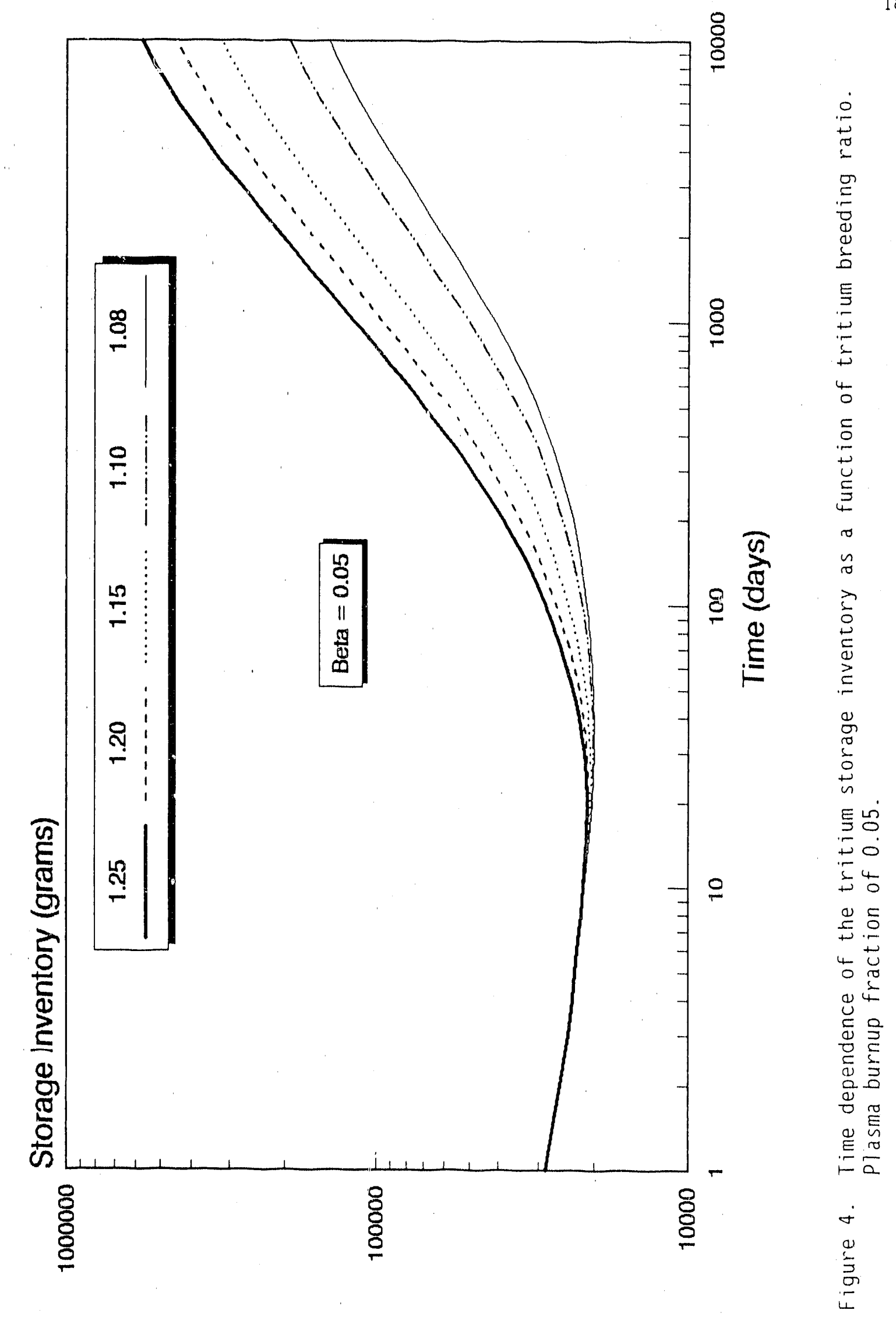




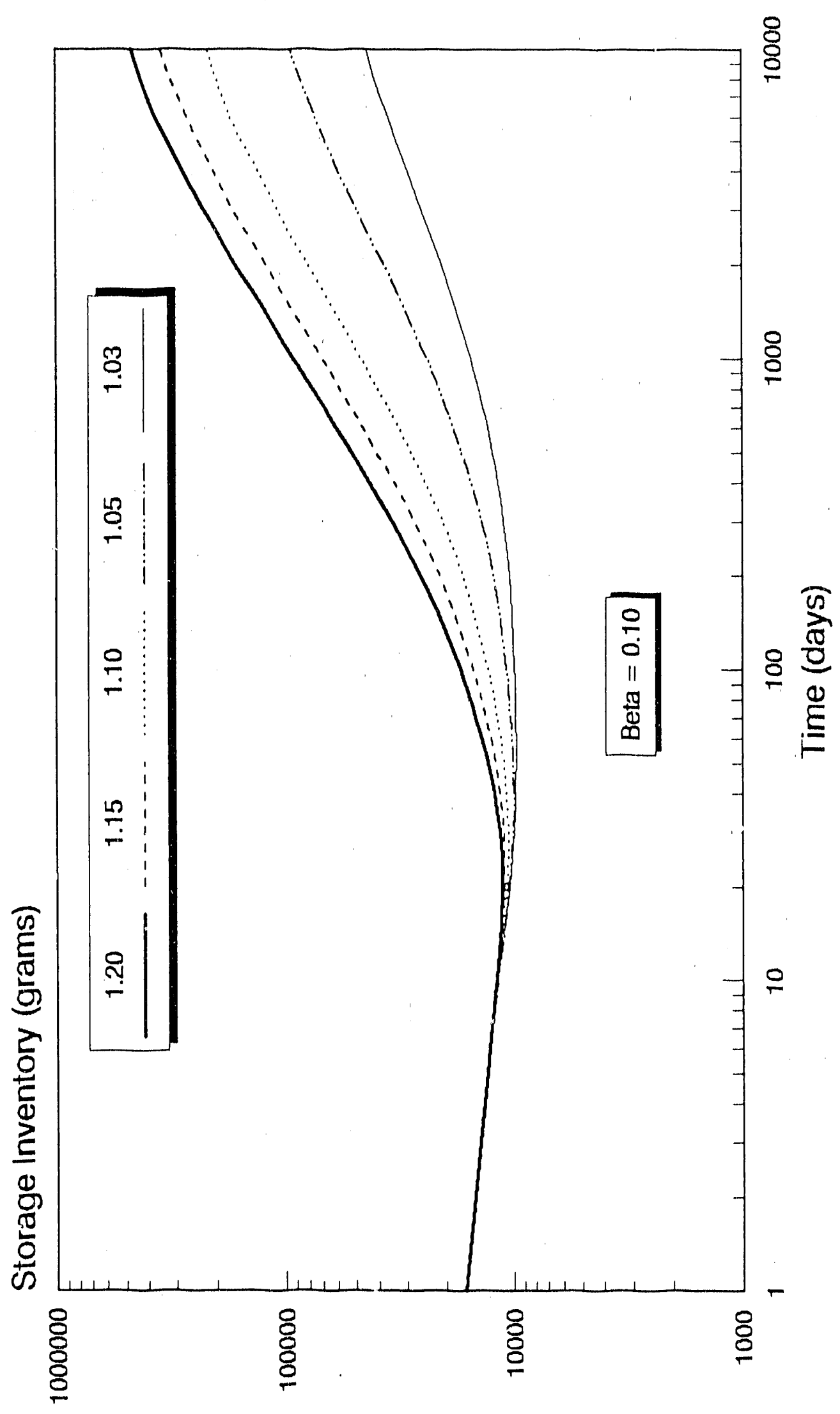




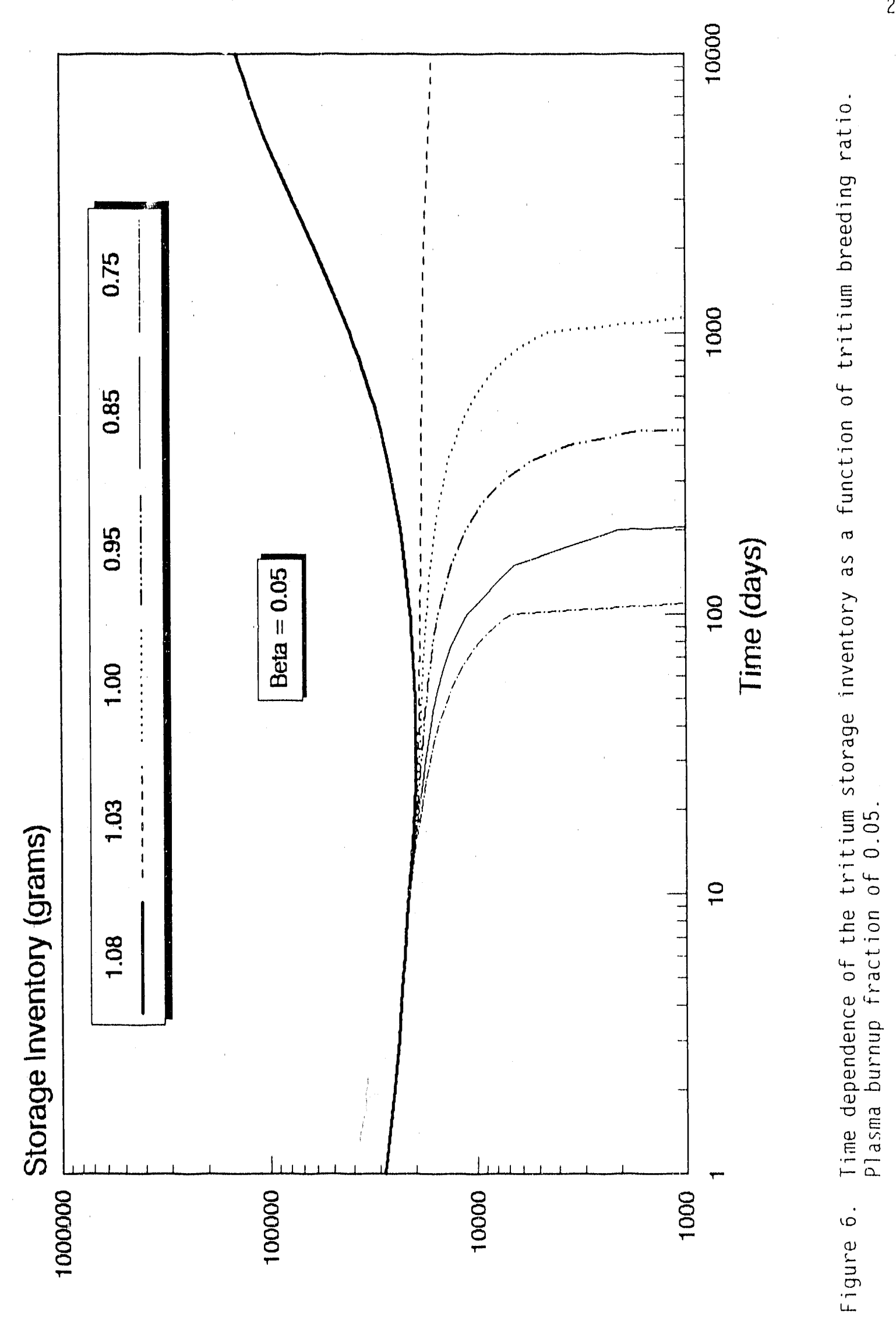

20 

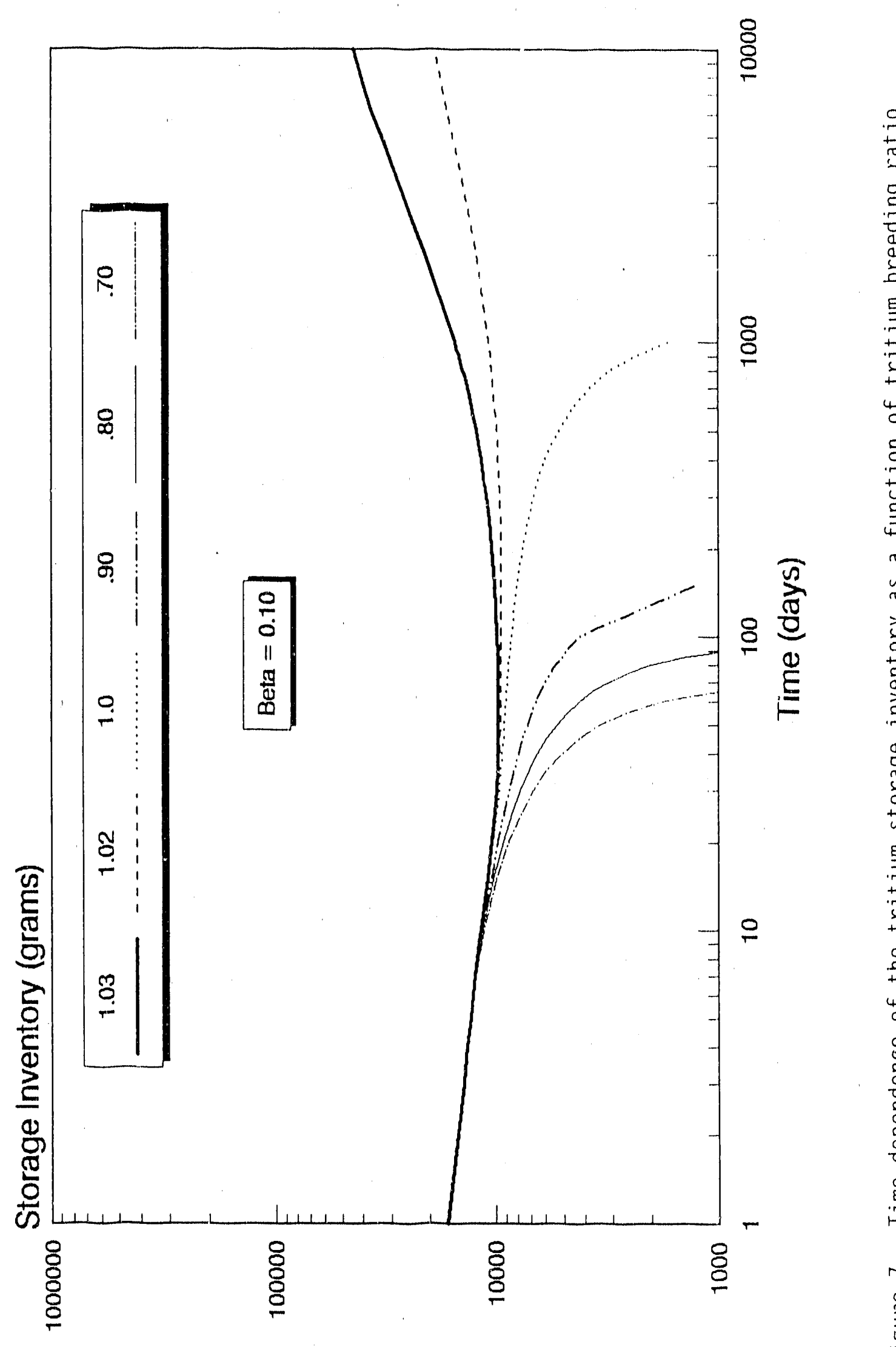

(5)

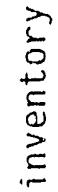

总

토으.

$\pm 0$

का

돈

4.

a) 4

음을

ํํำ

d

O

$r$

号 
Once a reasonable estimate of the stable TBR is has been found, it can be used to stabilize the tritium inventory in the storage system after the initial inventory has been recovered. Figures 8 and 9 present the time dependence of the tritium breeding ratio which is required to first recover the initial startup inventory of tritium in the storage component of the system and then to hold the storage inventory at the startup level.

The initial storage inventorv is achieved after approximately 650 days of ful1 power operation for a reactor system operating with a plasma burnup fraction of 0.05 and a TBR of 1.08 as suen in Figure 8 . At this point in time the TBR is reduced to 1.036 and held roughly constant. The resulting time dependence of the inveritories $i_{i l}$ various system compolients can be seen in Figure 1). It can be seen that after the change in the TBR the storage inventory doas indeed reach a stable value. It car be seen that slight adjustments in the equilibrium inventories in the other system components, iso occurs.

Similar results are seen in Figure 11 for a reactor system with a plasma burnup fraction of 0.10 and an initial TBR of 1.03. Once the initial tritium storage inventory is achieved after approximately 1900 days of full power operation the TBR is reduced to 1.0195. Again there are slight changes in the equilibrium invencuries of the other tritium system components as the storage inventory levels off.

\subsection{DOWN TIME CYCLE}

The first bit of realism that will be introduced to the analysis is the addition of an annual maintenance and blanket replacement shutdown. This means that the system is simulated to operate at full power for 11 months and then be shut down for 1 month to perform routine maintenance and to replace used blanket segments. Figures 12 and 13 show the tritium inventory in the storage system as a function of time for reactors with plasma burnup fractions of 0.05 and 0.10 respectively. These figures compare the inventory concentrations for a continuous operation mode to an operational cycle that includes an annual one month shutdown. The results show that the inventory values follow the same 


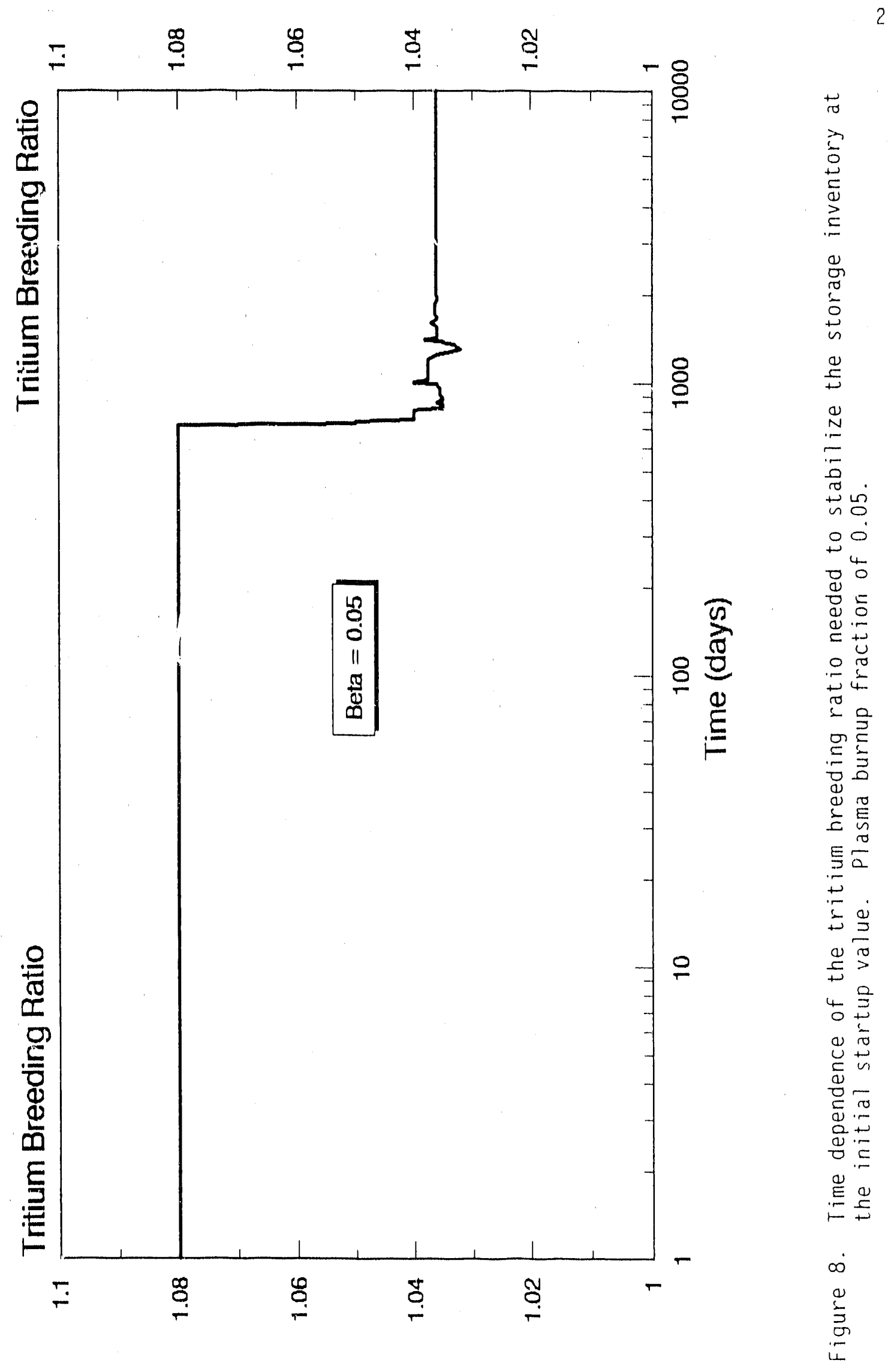




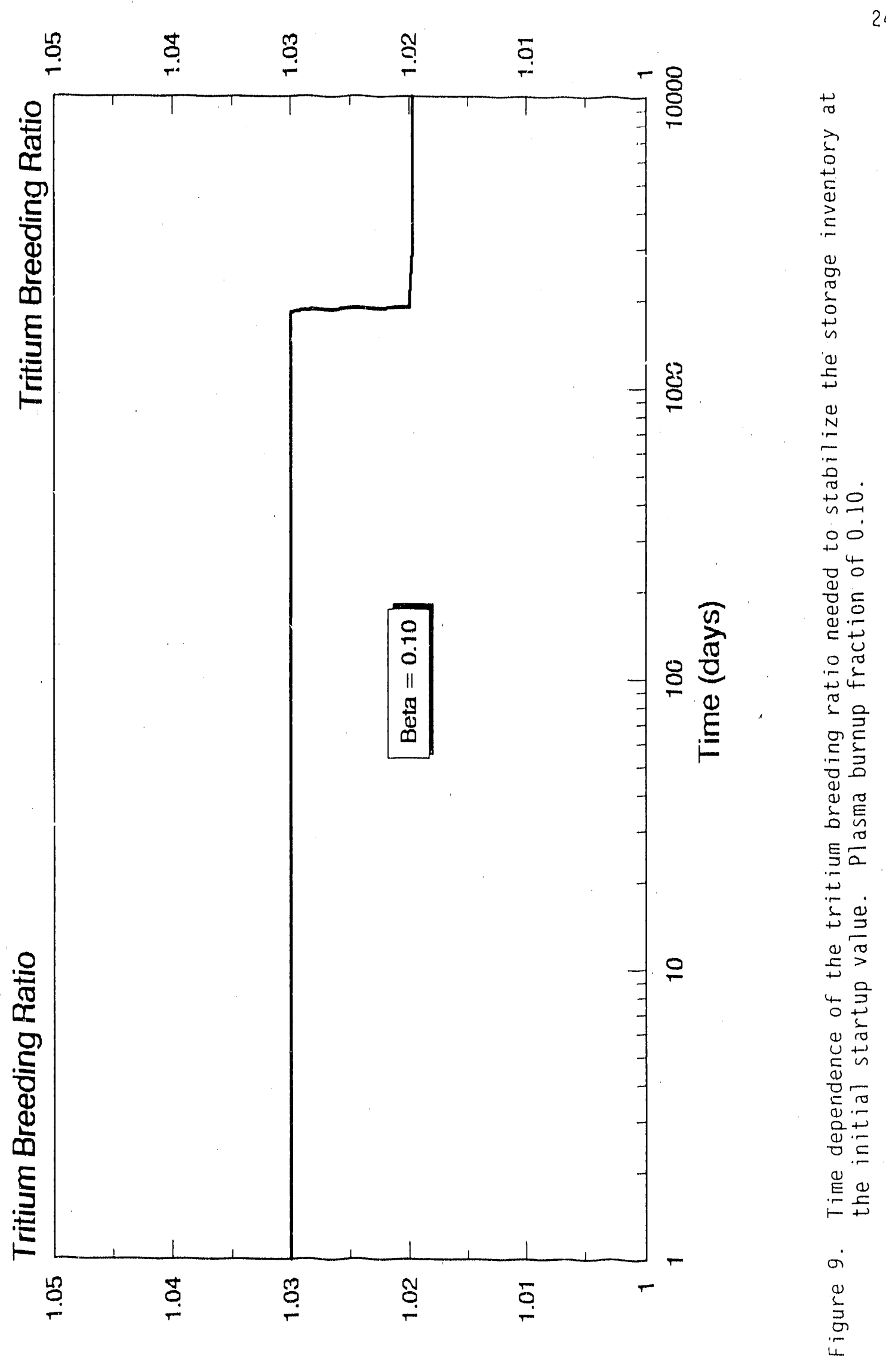




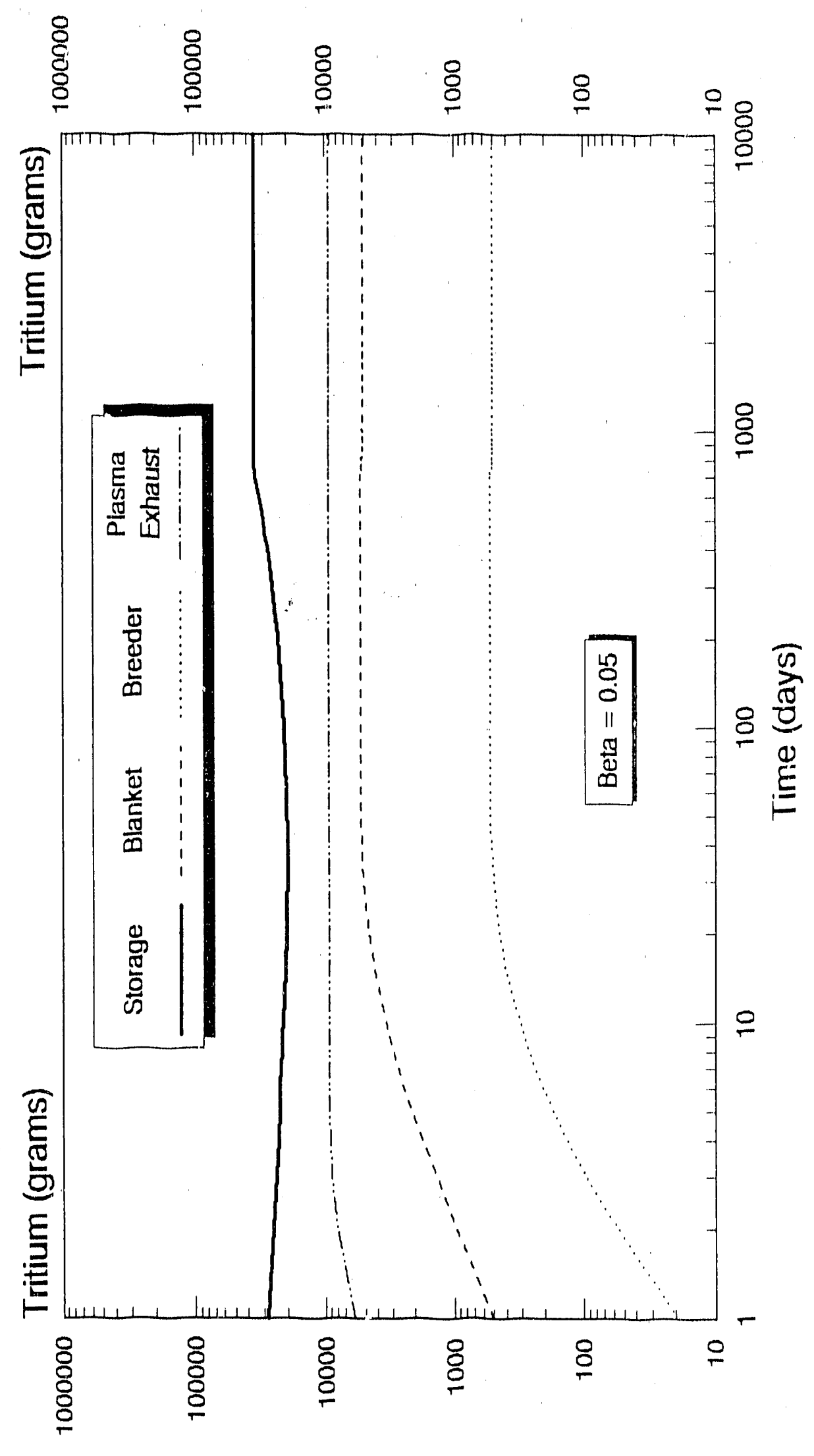

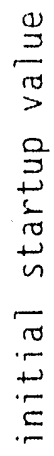

㐫

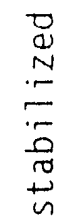

ธิ

을

$\geq$

0
0,4
0

立

莕

तो

을을

齐

E 틀

-

$=\frac{\pi}{2}$

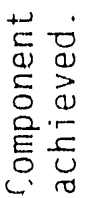

$\stackrel{\circ}{1}$

少 

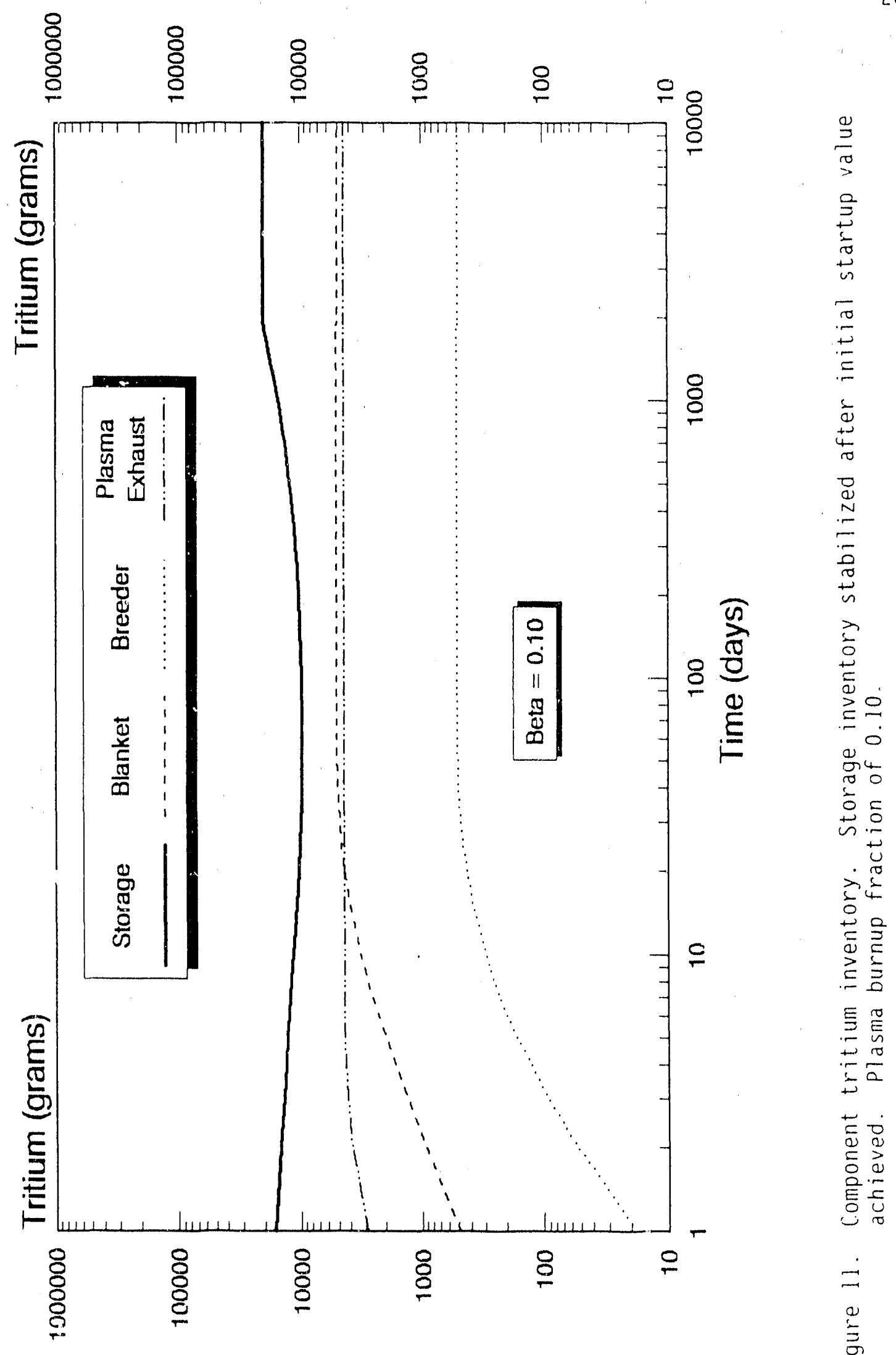

$\bar{\Xi}$
$\vdots$
$\frac{1}{5}$ 


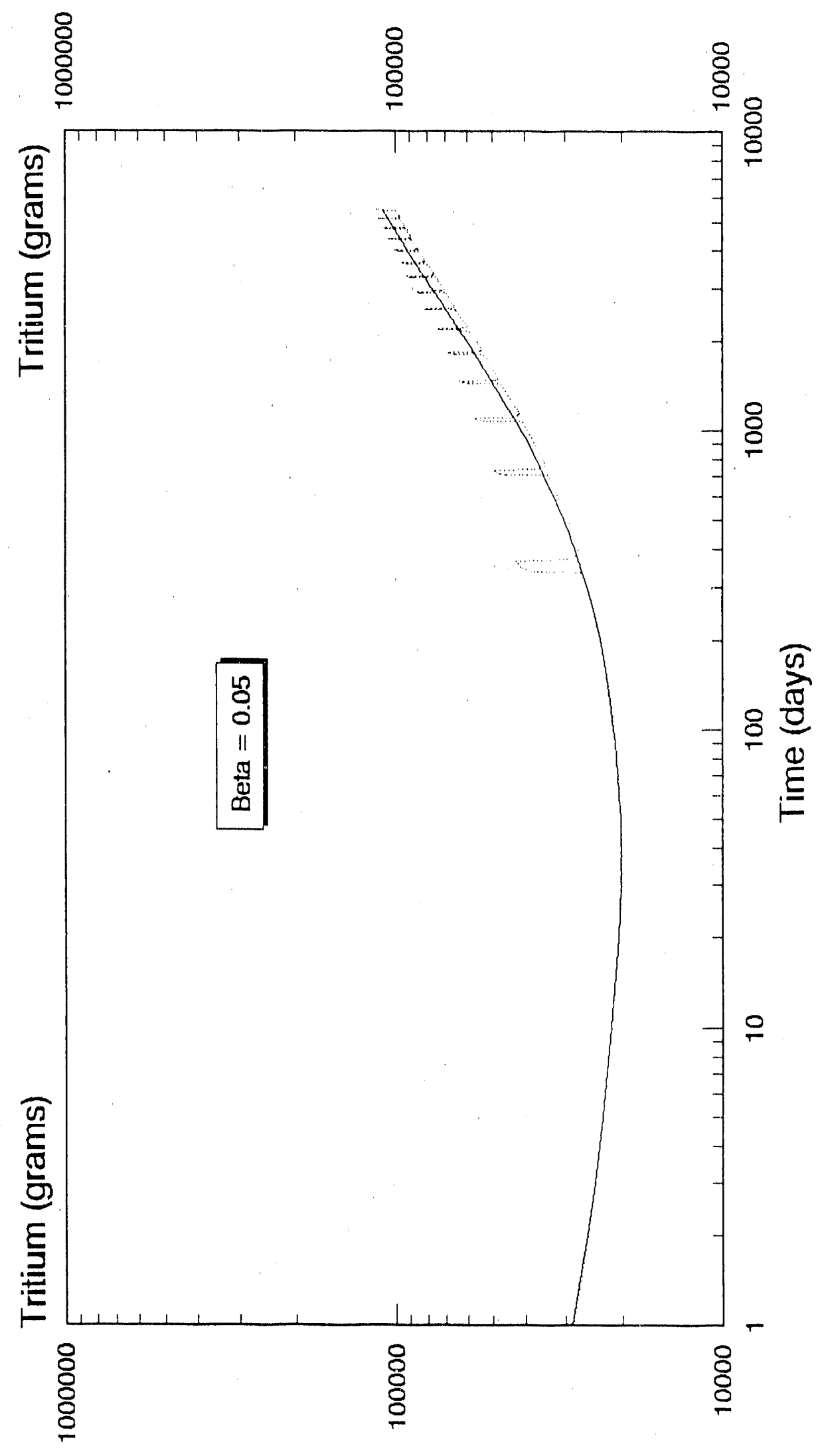

27

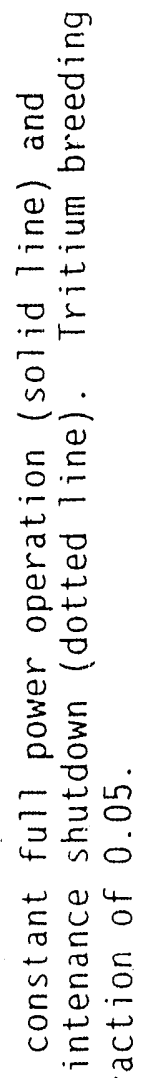

ᄃ

옫들

ᄂ.

तٓ듕

들

$\therefore \sum_{0}$

过

它 $\infty$

$\frac{1}{3} 0$.

जᄃㄴㄷㄴ

E

두요

$=\frac{0}{5}$

$\cong$

气 


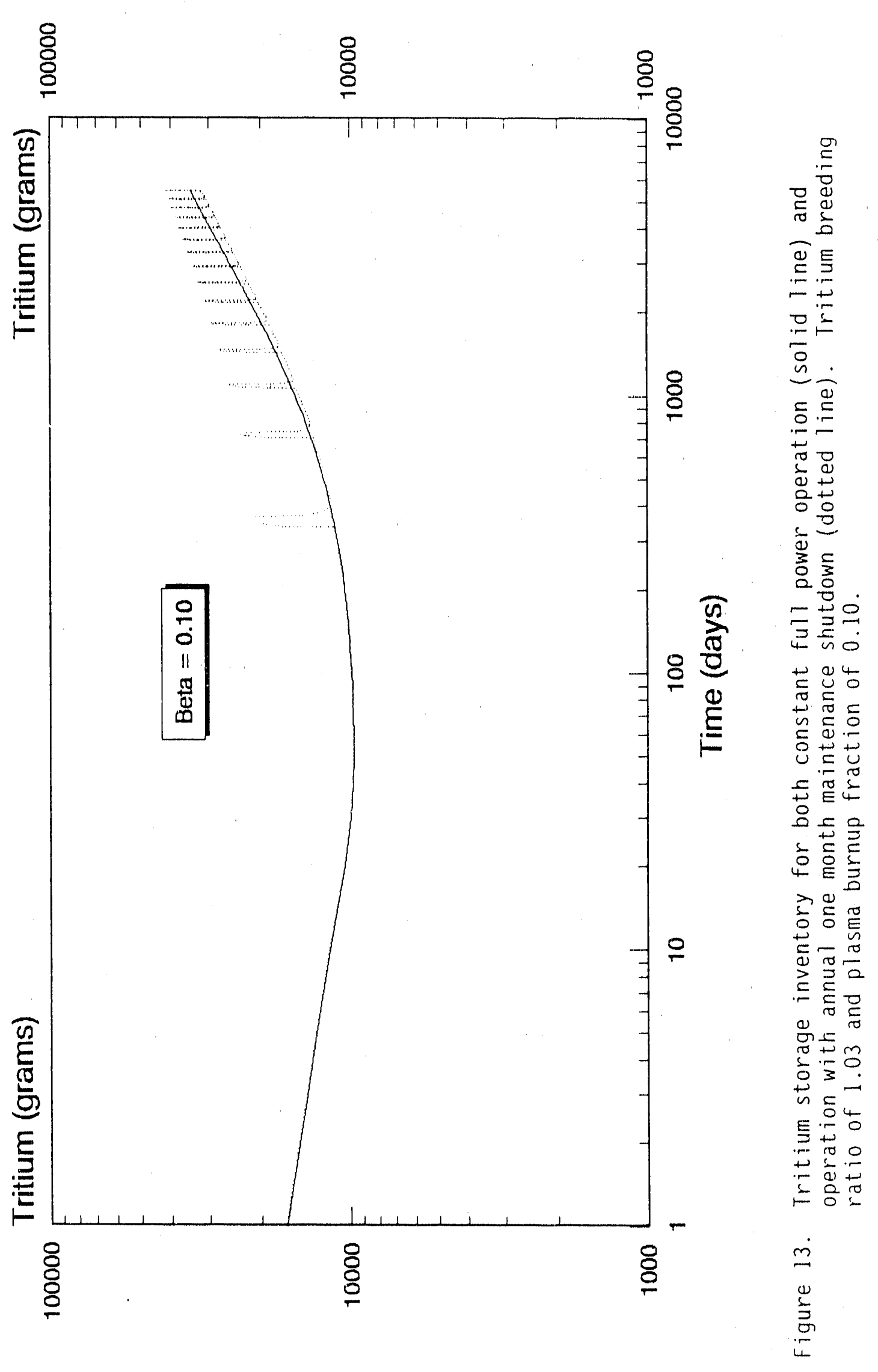


general trend for both operation modes, as would be expected. However, the cycle mode with the annual shutdown exhibits a storage inventory which is slightly lower than the continuous operations mode. This is to be expected because of the loss of 1 month of breeding time in the annual sh tdown cycle. Note also that there is a considerable increase in the storage inventory during shutdown as the other components in the tritium flow stream continue to process tritium.

Figures 14 and 15 are extensions of the previous two figures including the effects of reducing the TBR to stabilize the tritium storage at the initial storage inventory. An important conclusion to be drawn from this analysis is that different TBR values are needed to achieve a stable storage tritium inventory depending upon the mode of operation of the reactor system. In particular, the stable TBR values from section 5.2 were based on the continuous operation mode of the system. As can be seen in Figures 14 and 15 the values found previously will be insufficient to maintain the tritium inventory in storage if the system is on a more realistic operation cycle over the life of the plant. Fortunately, the difference does not require a large adjustment in the TBR to attain an equilibrium storage inventory, or depress the inventory to a Targe degree.

\subsection{COMPONENT FAILURE}

The next phase of potential actual system operation is to evaluate the failure of various components in the tritium handling system. The key questions to answer here are:

- How is the tritium inventory in the storage system affected by the loss of a processing system elsewhere in the plant?

and

- Is it at all possible to continue operations if certain tritium systems need to be removed from service while the plant continues to operate? 


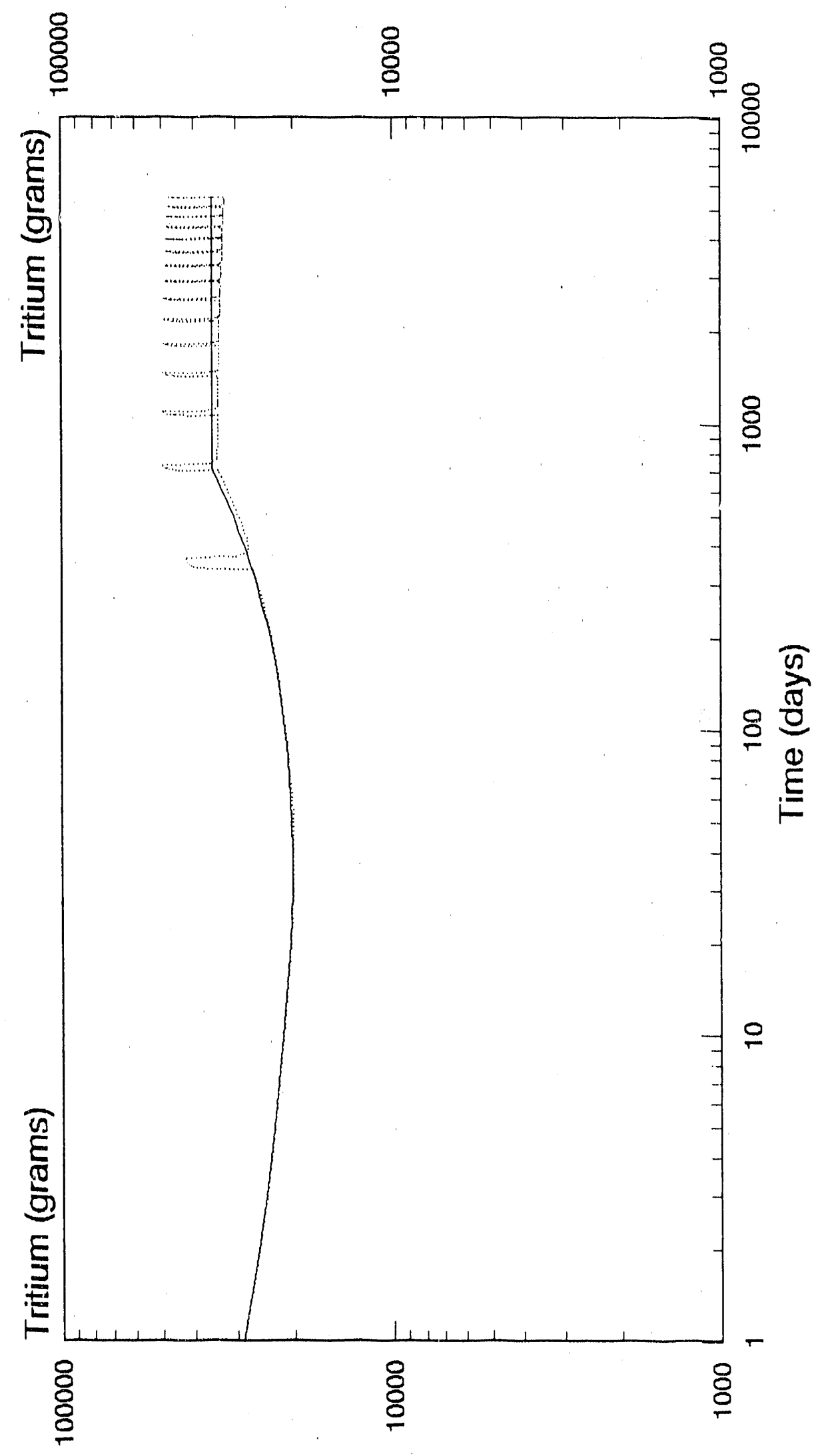

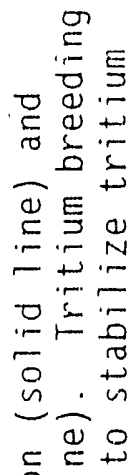

$\therefore=10$

๑ 0

क

$2+$

뭉

文

క气 品.

음동용

三出它。

는

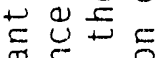

\%

¿

ᄃ험

$\cup \equiv 0_{4-}^{5-}$

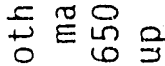

든

ธ등 ฮิ

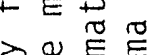

ऽ国㧫

우이

뒤음

$\geq \vec{~}$

$=$ 否-

व

开政

ป 3

isco.

E $\therefore$ - 0

范。品

ㄷㄴ.

5 유ㅇㅛㅛ

$\dot{\square}$

吉 


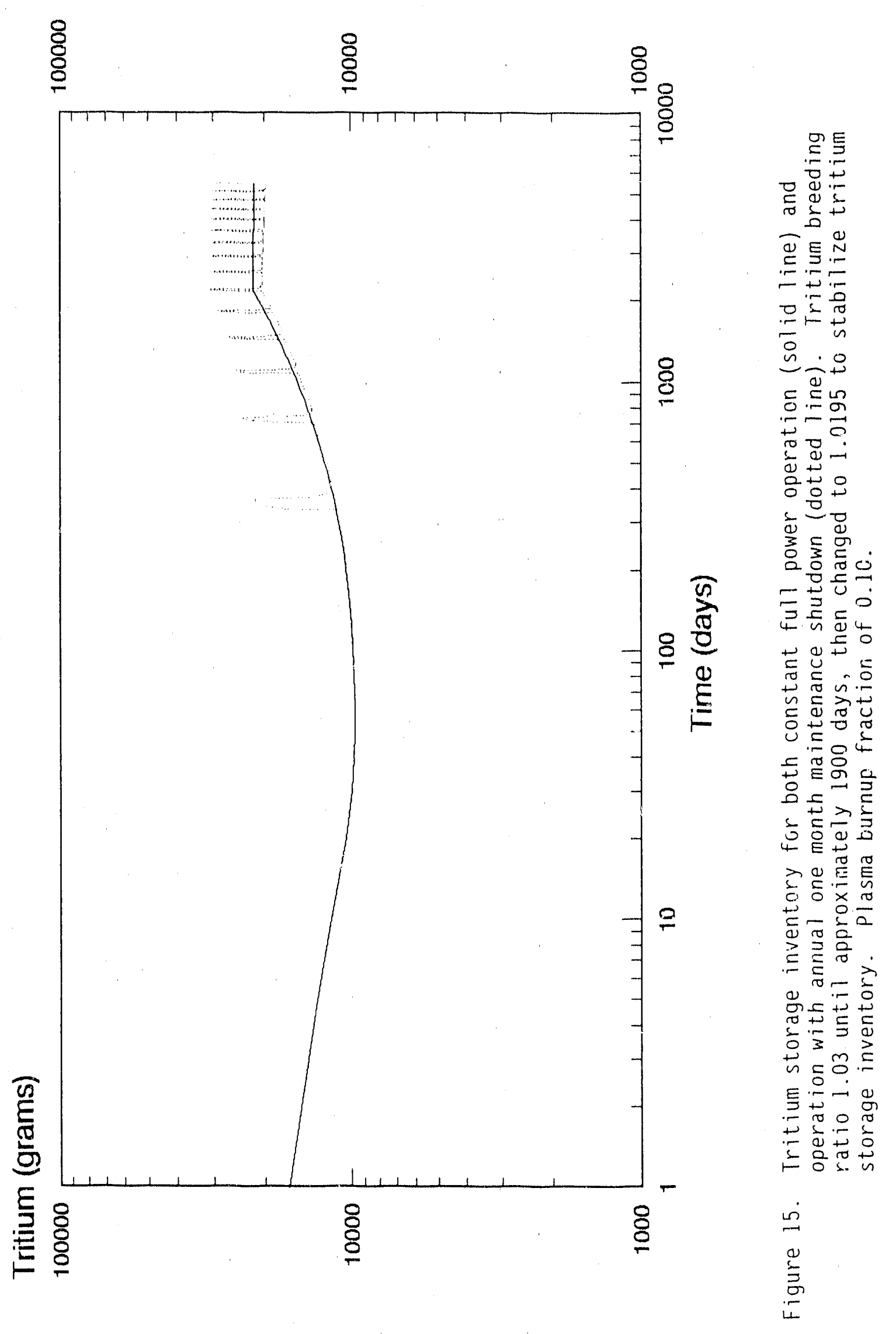


Again, it is instructive to look at the two reference cases of plasma burnup fraction of 0.05 and 0.10 . For the purpose of illustration, component failures which occur 30 days after startup were evaluated. This time was chosen because the systems which were evaluated in the previnus sections typically had their lowest storage inventory at ahout 30 days aiter startup.

The systems which have been allowed to fail include the Blanket, Breeder, Fuel Cleanup, and Plasma Exhaust Systems. Figure 16 shows the results of the failure of these systems on the storage inventory for the case of plasma burnup fraction equal to 0.05 , and Figure 17 shows the effects of components system failures on the storage inventory for the case of plasma burnup fraction equal to 0.10. In both cases, it was discovered that the tritium inventories in storage are drastically changed. Both cases show that continued operation after a system failure is not possible for an extended period of time. This is especially true in the case of the failure of either the Fuel Cleanup or Plasma Exhaust systems. Only short term operation (a few hours at most) is possible with either of these components taken out of service because of their large tritium throughiut. If repairs to these components can be effected in less ihan a few hours it may be possible to continue to operate the reactor, however it is more likely that the reactor operator would shutdown the entire reactor should one of these systems need repair or replacement. This analys is also points out the need for complete backup systems held in standby should these important systems suffer a failure. The addition of standby backup systems would increase the overall plant availability. Lxtended plant operation (five to ten days) with a failure in either the Blanket Tritium System or the Breeder Processing system may be allowable if these systems can be readily repaired or rep aced since their effect on the reduction of the storage tritium inventory is considerably smaller.

Another important result of component failure is what happens to the inventory in the various system components if the plant continues to operate while on line repairs are made. In addition to a drop in the storage inventory, there will be a buildup of tritium in the failed system. Figure 18 shows the tritium bulildup in the failed component in comparison to the reference case of no failure for a reactor system with a plasma burnup fraction 0.05 . This figure shows that there is a dramatic increase in the tritium inventory in the failed 


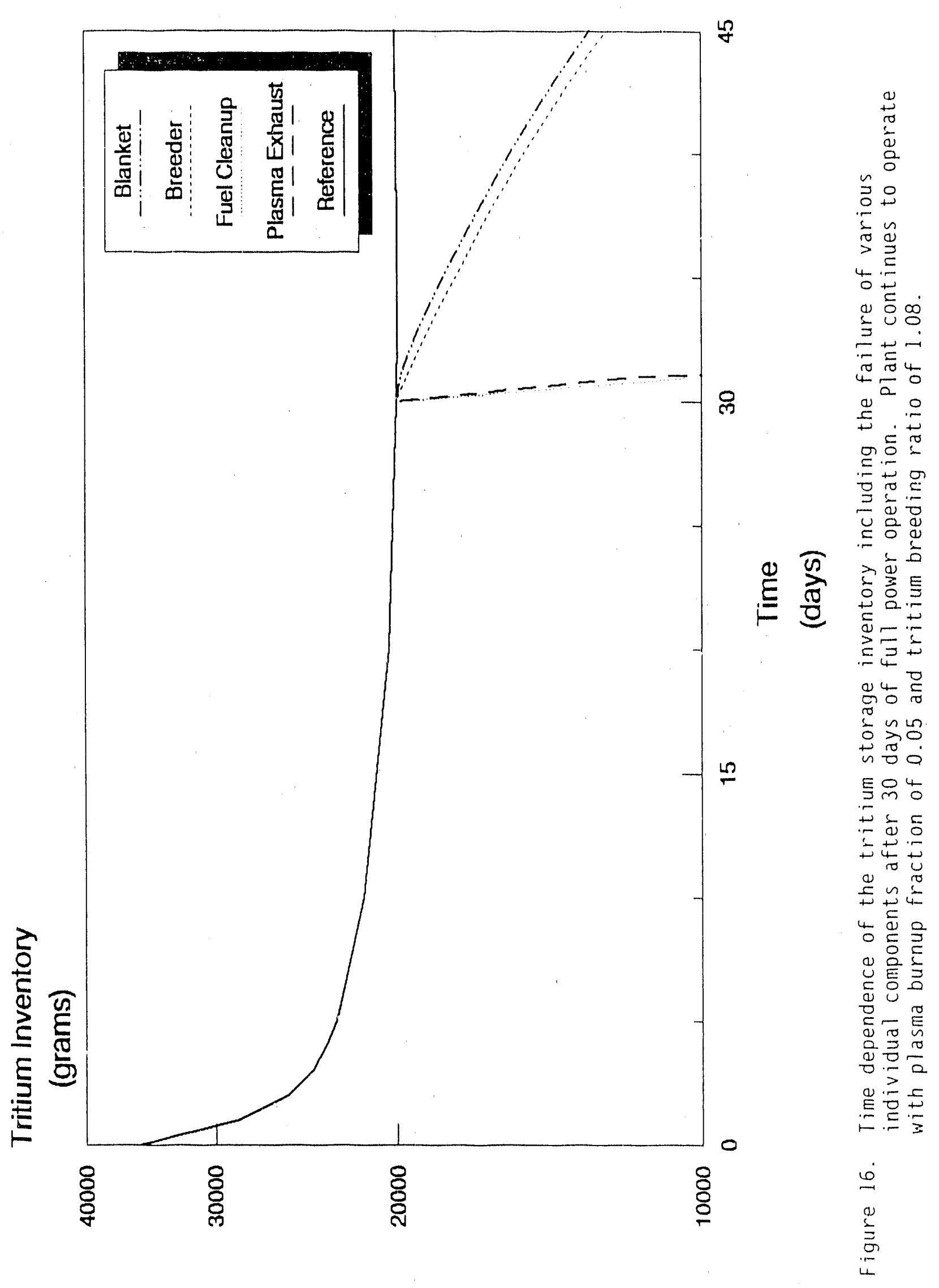




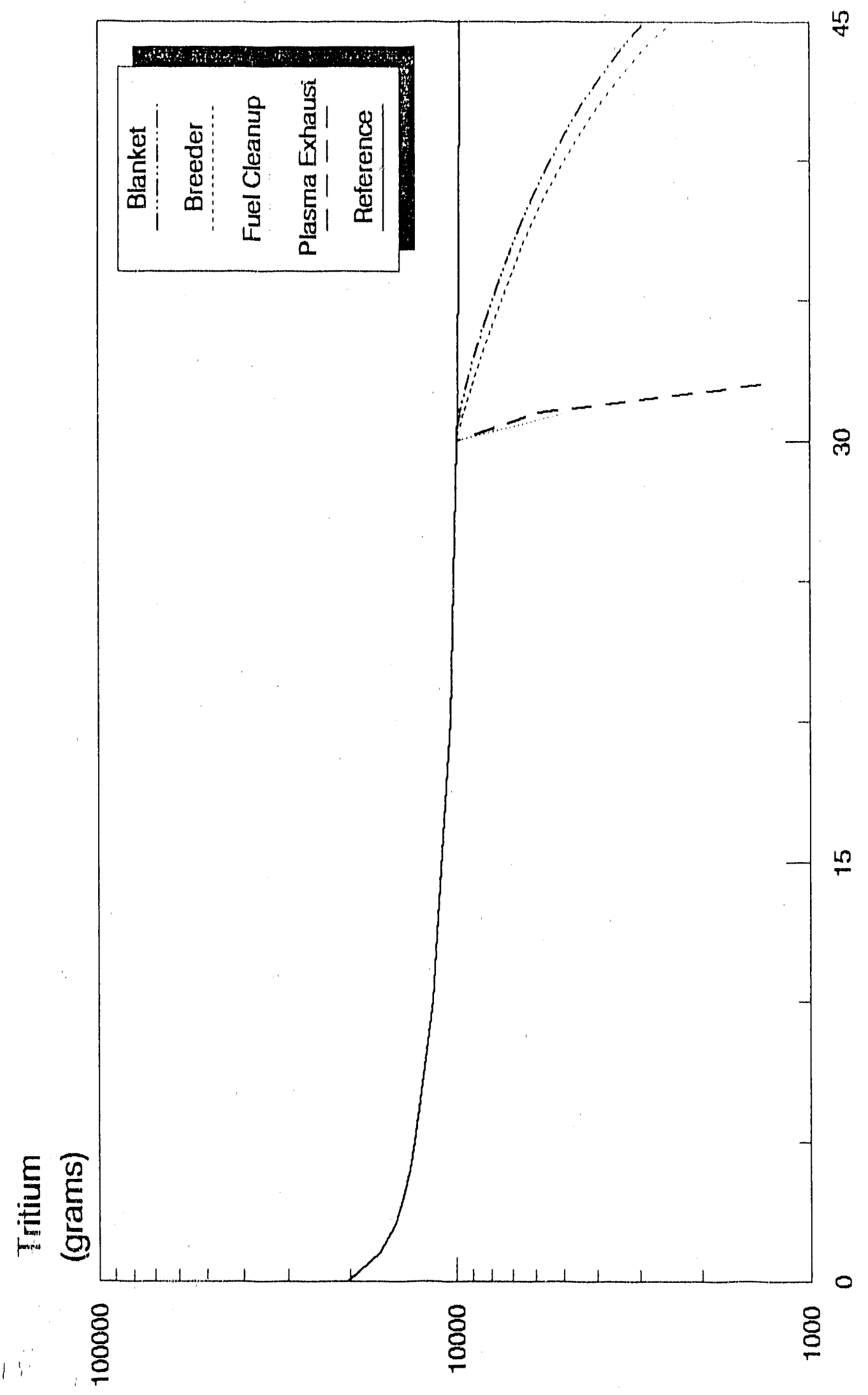

$\frac{9}{0}$

ติำ

它

$>$ ᄅ

4.

\&

工二

둔

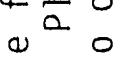

岳.

몽ํㅇ

苛范

בิ

능 웡

(1) ज $7 \frac{1}{2}$

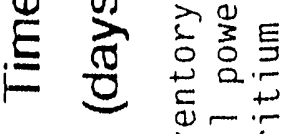

专立

40

ติ

느으

뇨

出

통 4

$\varpi 5$

$= \pm$

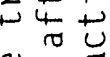

$\stackrel{5}{2}$

Ф

넝을

U 을

ق.

T

ट

웜도

व.

惫总吾

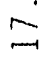

紊 


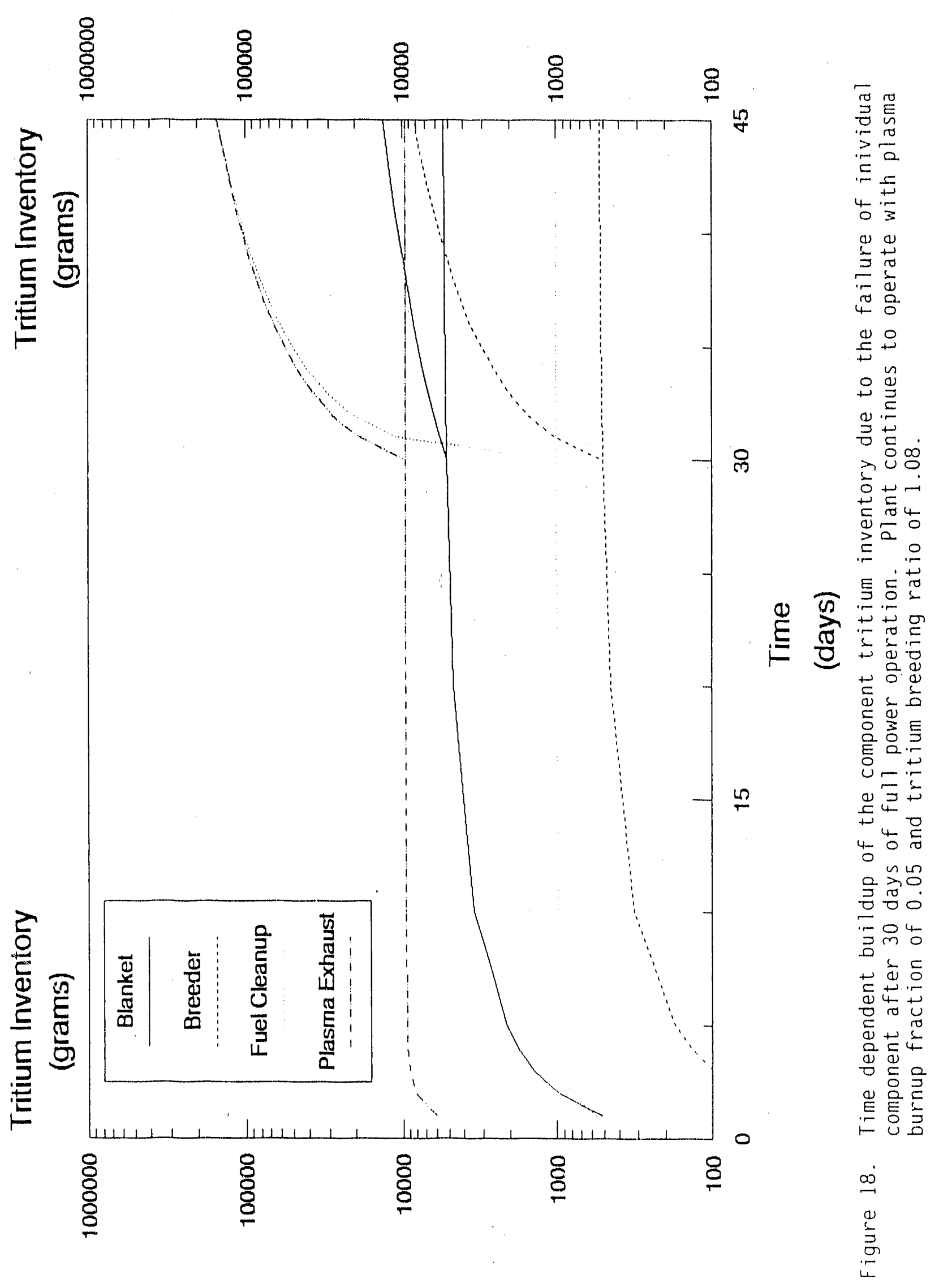




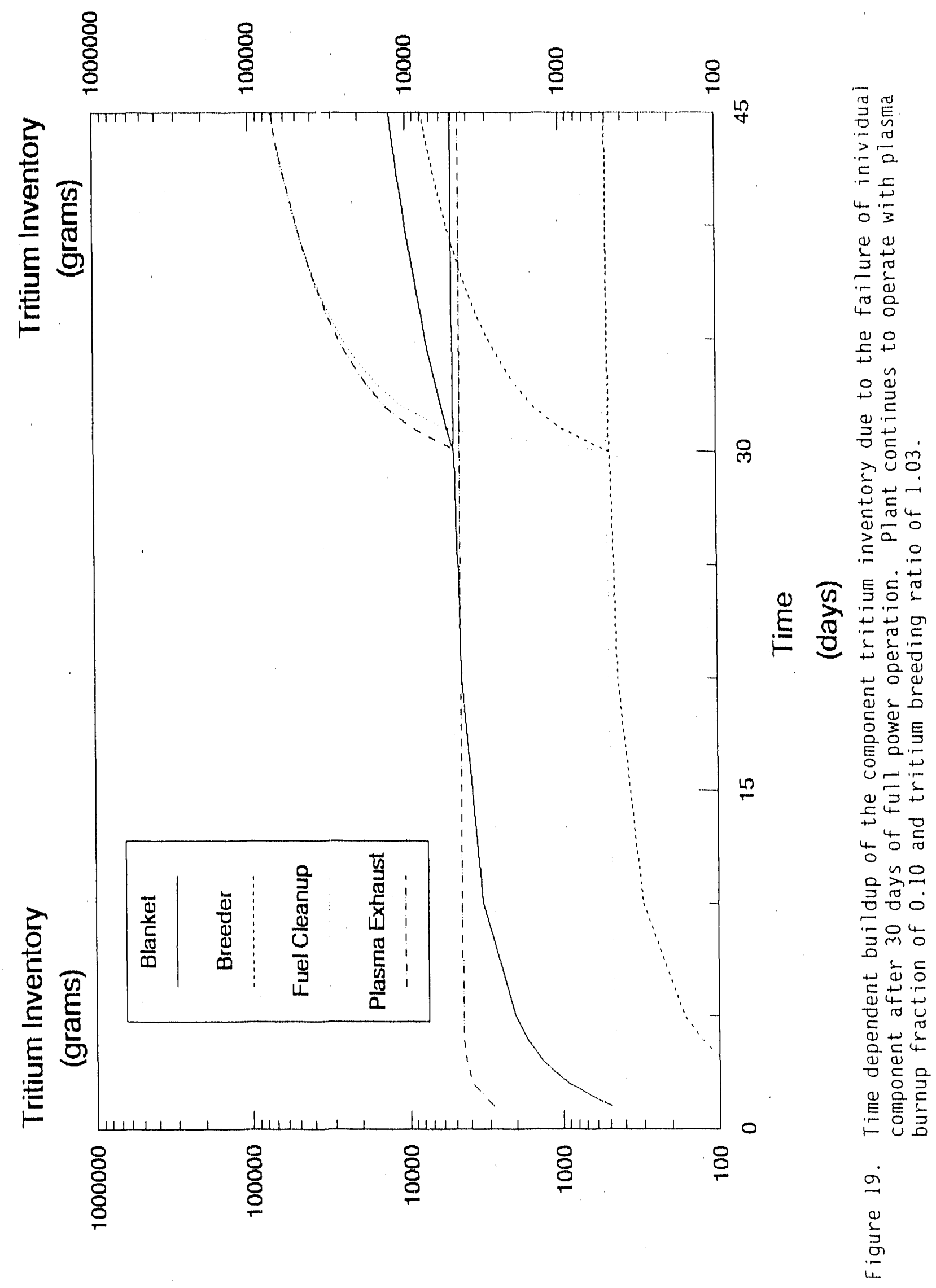


system under continued operation. The iriventory increase is particulariy large for a fallure of the Fuel Cleanup system, where the system inventory increases by more than an order of magnttude in Just 2 days and over 2 orders of magnitude within 2 weeks. Figure 19 presents a similar analysis for a reactor with a plasma burnup fraction of 0.10 . This figure also shows the same trends in tritium buildup in a failed component.

\subsection{STARTIJP PRODUCTION}

One possible reason that a fusion power plant operator would want to produce excessive amounts of tritlum is to provide the inttial startup material for a new plant. Figure 20 shows the time dependence of the storage tritium inventory in a reactor with a plasma burnup fraction of 0.05 which is driven to produce a doubling of the storage tritium inventory over the period of one and two cycles. In this case the TBR has been increased to 1.1725 to achieve a doubling of the storage tritium inventory in a single cycle, and to 1.105 to double the storage inventory over two cycles for use at a new power plant.

Figure 21 shows the results for a similar analysis for a reactor with a plasma burnup fraction of 0.10 . In this case the TBR which is needed to double the storage tritium inventory in one cycle is 1.0825 , and over two cycles it is approximately 1.053. It is obvious that the changes in tritium production which are needed to achieve the short term doubling of the storage tritium inventory are much easier to accomplish for a reactor which operates with as high a plasma burnup fraction as possible.

\subsection{CONCLUSIONS}

This investigation has identified a number of usefur applications of the analysis of the tracking and management of the tritium inventory in the various subsystems and components in a DT fusion reactor system. Due to the large amounts of tritium that will need to be circulated within such a plant, and the hazards of dealing with the tritium an electricity generating utility may not wish to also be in the tritium production and supply business on a full time 


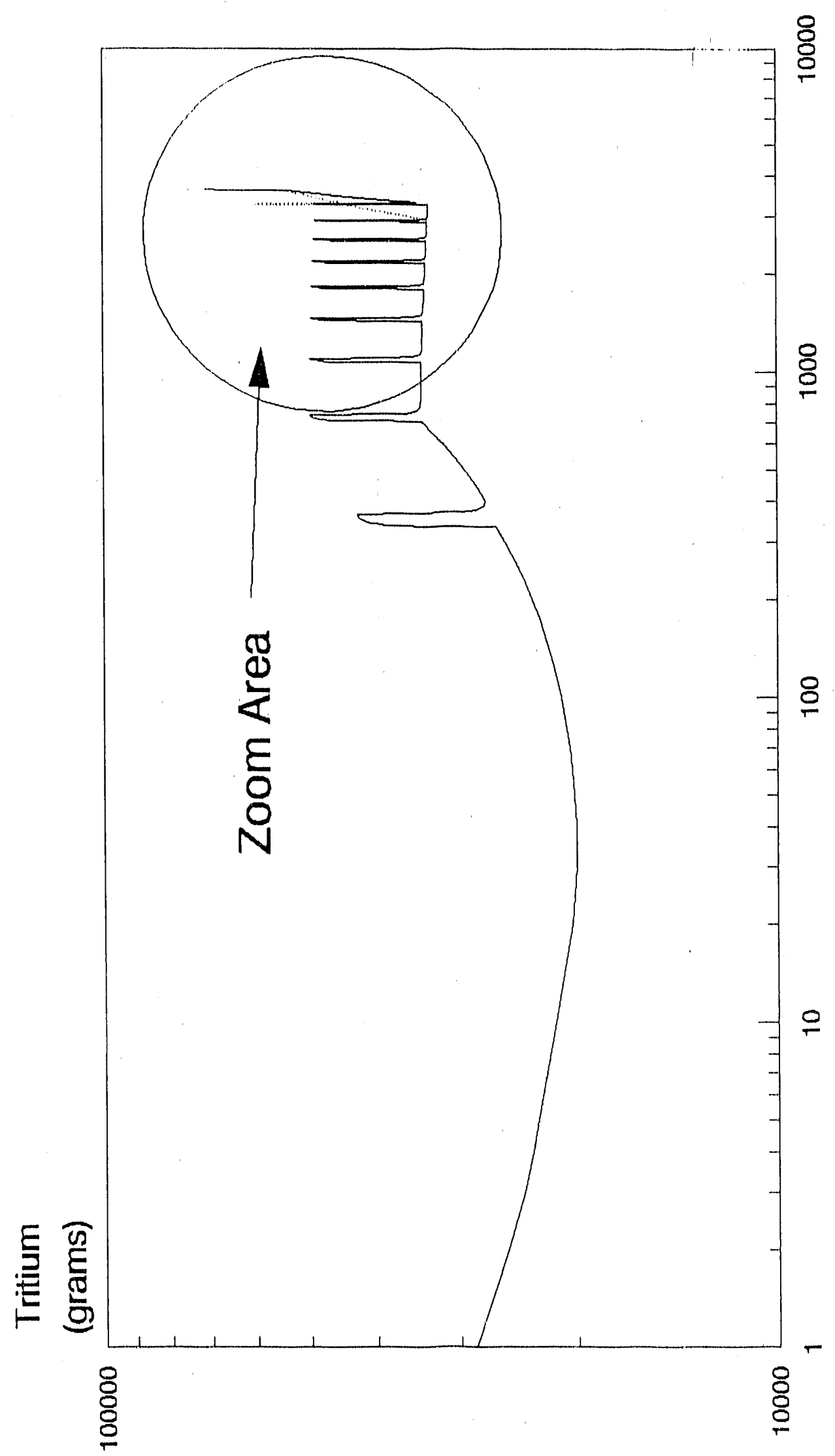

至

$\stackrel{ه}{ \pm}$

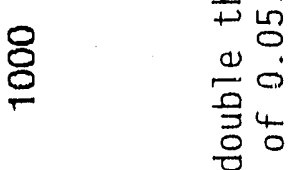

온

$\circ$ 艺

$\pm 2$

2

을

E

몽

\&.

틀

$\pm$

+

요

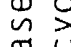

잉

$\Xi$

.

خิ๊

ญิ $\subseteq$

व

Oे

○

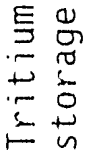

$\stackrel{0}{\stackrel{0}{0}}$

少 


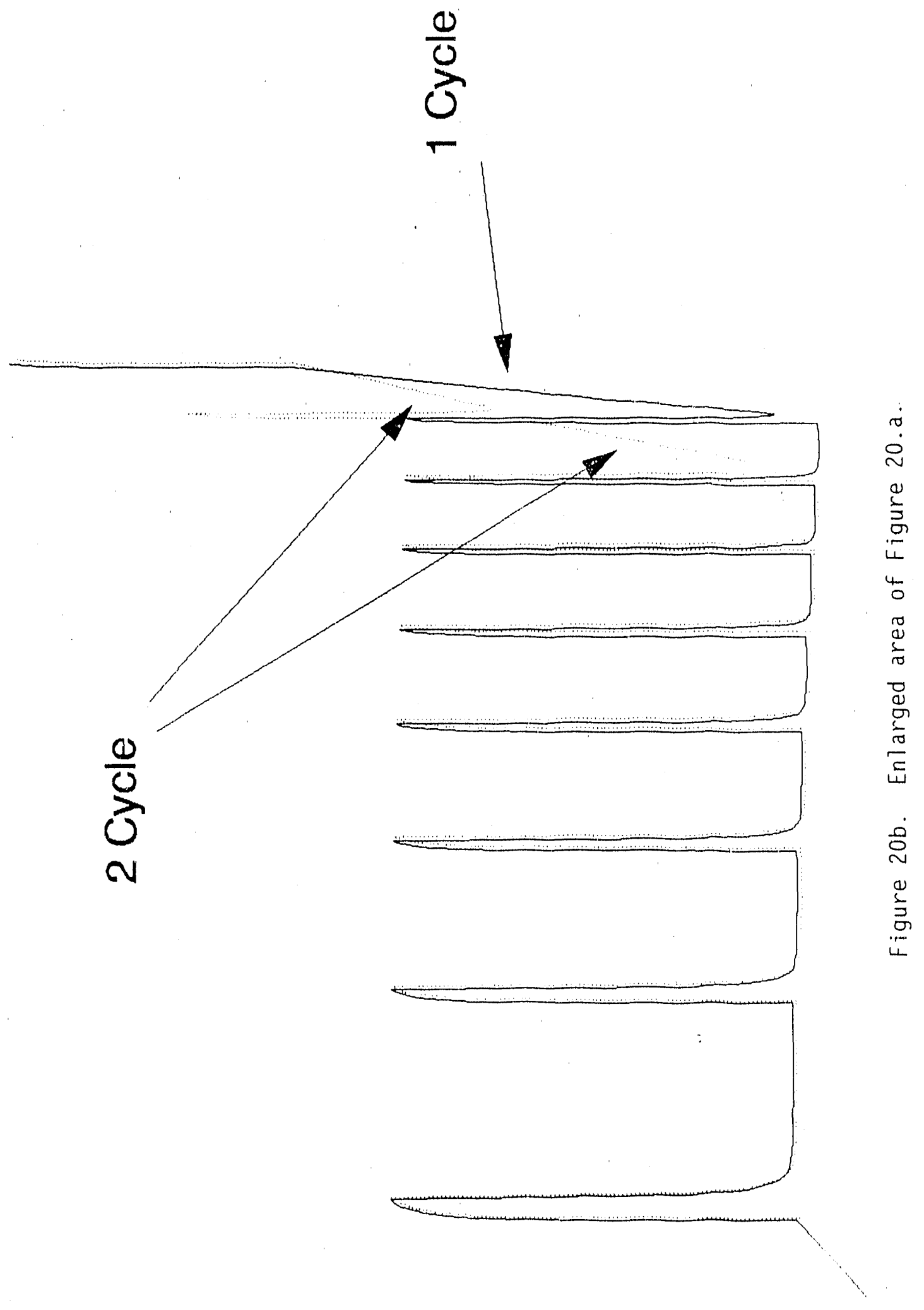




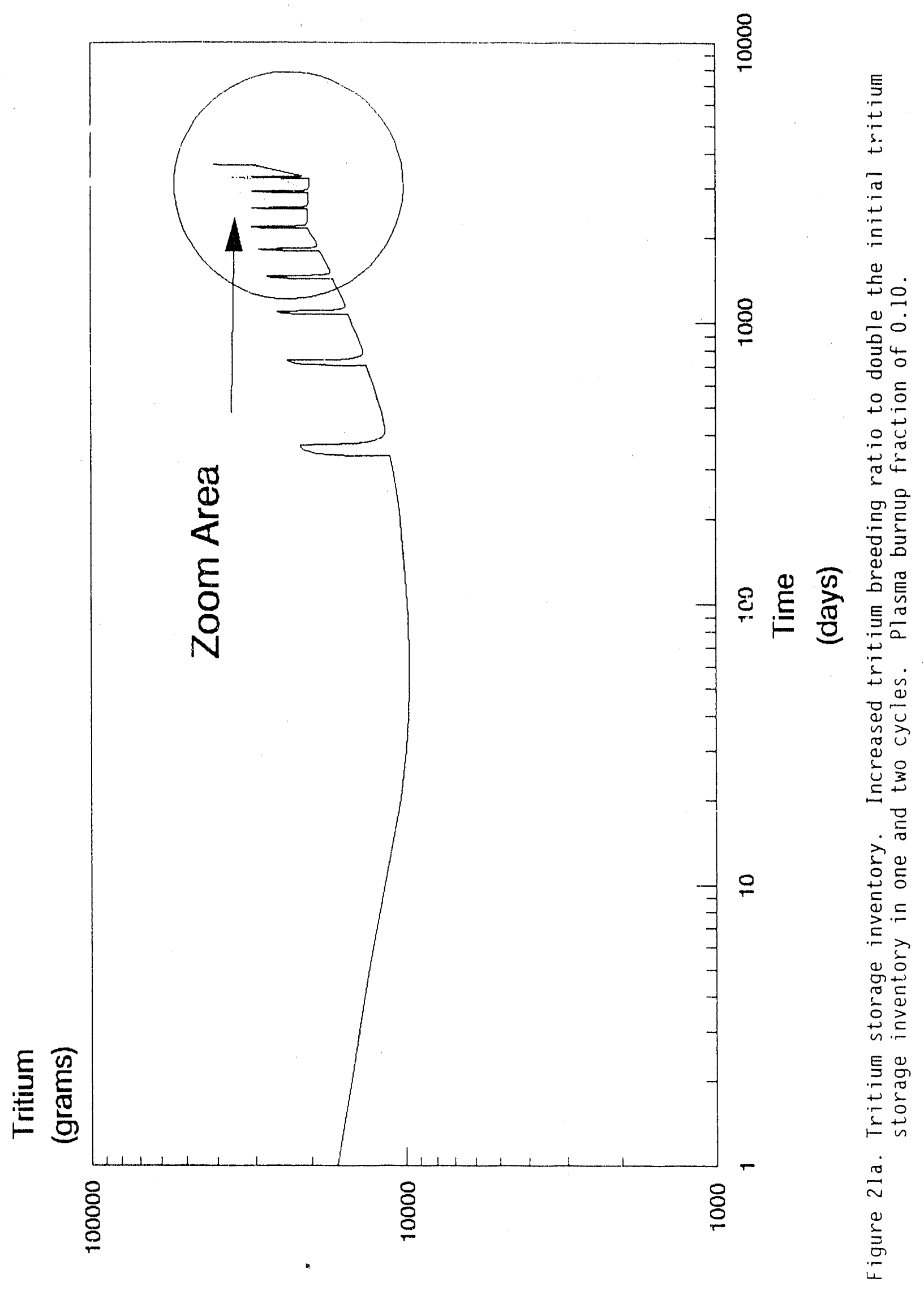

40 


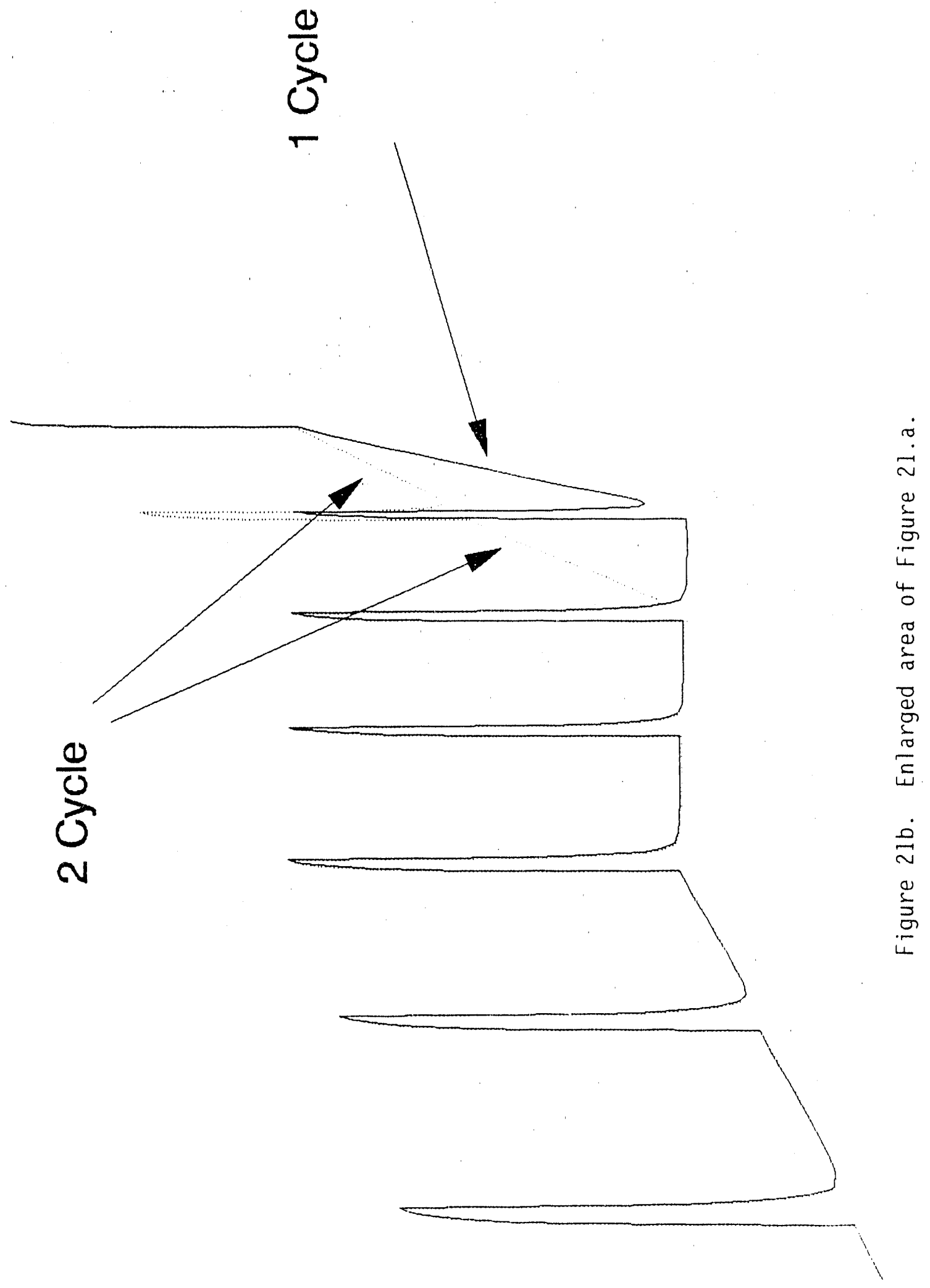


basis. Possible scenarios for system operation have been presented, including options with zero net increase in tritium inventory, annual maintenance and blanket replacement, rapid increases in tritium creation for the production of additional tritium supplies for new plant startup, and failures in certain system components.

It has been found that the value of the tritium breeding ratio required to stabilize the storage inventory depends strongly on the value and nature of other system characteristics. The real operation of a DT fusion reactor power plant wi11 include maintenance and blanket replacement shutdowns which will affect the operation of the tritium handling system. It was also found that only modest increases in the tritium breeding ratio are needed in order to produce sufficient extra tritium for the startup of new reactors in less than two years. Thus, the continuous operation of a reactor system with a high tritium breeding ratio in order to have sufficient supplies for other plants is not necessary. Lastiy, the overall operation and reliability of the power plant is greatly affected by failures in the fuel cleanup and plasma exhaust systems. Failures in these systems will require the shutdown of the plant. The continued operation of the reactor after the failure of the blanket tritium system or the breeder processing system for up to five to ten days may be possible if repairs can be affected within that length of time.

\subsection{ACKNOWLEDGEMENTS}

This effort was supported by the U.S. Department of Energy, Office of Energy Research, Office of Fusion Energy under grant number DE-FG06-88ER52152. The authors also wish to thank D.-K. Sze, Argonne National Laboratories, and other members of the Advanced Reactor Innovations and Evaluations Study (ARIES) for their contributions and discussions during the course of this work.

\subsection{REFERENCES}

1. Vogelsang, W.F., "Breeding Ratio, Inventory, and Doubling Time in a D-T Fusion Reactor," Nuclear Technology, 15, 470, 1972. 
Jung, J. and Abdou, M.A., "Assessments of Tritium Breeding Requirements and Breeding Potential for the STARFIRE/DEMO Design," Nuclear Technology/Fusion, 4, 361, March 1983.

3. Jung, J., "An Assessment of Tritium Breeding Requirements
Tritium Fuel Cycle," Fusion Technology, 9, 308. March 1986.

4. Abdou, M.A., Vold, E.L., Gung, C.Y., Youssef, M.Z., and Shin, K., "Deuterium-Tritium $F(t)$ Self-sufficiency in Fusion Reactors," Fusion Technology, 9, 250 (186).

5. Lee, C.E., "Calculat" of Isotopic Mass and Energy Production by a Matrix Operator Method,"
Alamos, NM, August 6.

6. F.R. Gantmacher, ITheory of Matrices, Chelsen Publishing, New York, 1960.

7. C.E. Lee, et al., ssion Product Release Calculations from a Reactor Containment Buildi Nuclear Sci. and Engr., 64, 1, September 1977.

C.W. Miller and Olermann, "ANEMOS: A Code to Calculate Radionuclide Concentrations in" Irans. Am. Nucl. Soc., 38, June 1981.

9. Klein, A.C. and vang, W.F., "RAPTOR: A Computer Code to Calculate the Transport ofvation Products in. Fusion Reactors," UWFDM-567, University of Wis, 1984.

0. A.C. Klein, "Actn Product Transport in Fusion Reactors, " Ph.D. Thesis, Universitisconsin, Madison, WI, 1983.

11. A.C. Klein and logelsang, "Radiation Hazards Due to Activated Corrosion and Neputtering Products in Fusion Reactor Coolant and Tritium Breeding," Nuclear Engr. and Design/Fusion, 2, 4, July 1985. 
